\title{
PATHOLOGY/BIOLOGY
}

Zachary M. Burcham, ${ }^{1}$ Ph.D.; Caitlyn A. Cowick, ${ }^{1}$ B.S.; Courtney N. Baugher, ${ }^{1}$ B.S.; Jennifer L. Pechal, ${ }^{2}$ Ph.D.; Carl J. Schmidt, ${ }^{3}$ M.D., M.P.H.; Jason W. Rosch, ${ }^{4}$ Ph.D.; M. Eric Benbow, ${ }^{2,5}$ Ph.D.; and Heather R. Jordan, ${ }^{1}$ Ph.D.

\section{Total RNA Analysis of Bacterial Community Structural and Functional Shifts Throughout Vertebrate Decomposition ${ }^{\dagger, \ddagger}, \S$}

\begin{abstract}
Multiple methods have been proposed to provide accurate time since death estimations, and recently, the discovery of bacterial community turnover during decomposition has shown itself to have predictable patterns that may prove useful. In this study, we demonstrate the use of metatranscriptomics from the postmortem microbiome to simultaneously obtain community structure and functional data across postmortem intervals (PMIs). We found that bacterial succession patterns reveal similar trends as detected through DNA analysis, such as increasing Clostridiaceae as decomposition occurs, strengthening the reliability of total RNA community analyses. We also provide one of the first analyses of RNA transcripts to characterize bacterial metabolic pathways during decomposition. We found distinct pathways, such as amino acid metabolism, to be strongly up-regulated with increasing PMIs. Elucidating the metabolic activity of postmortem microbial communities provides the first steps to discovering postmortem functional biomarkers since functional redundancy across bacteria may reduce host individual microbiome variability.
\end{abstract}

KEYWORDS: forensic science, postmortem interval, postmortem microbiome, necrobiome, decomposition ecology, metatranscriptomics

One of the most important issues facing the legal system is the development of a defendable, unbiased, and reproducible process to accurately determine time since death, or postmortem interval (PMI). These data are critical for determining whether a death is within the bounds of medicolegal relevance. This determination, however, is often challenging, as interpretation of data relevant to the case might be subject to confounding factors that could introduce bias or distort PMI estimates (1-5). Investigation begins with body examination and evidence collection at the scene and proceeds through history, physical examination, laboratory tests, and diagnosis that should be handled in a scientifically defensible

\footnotetext{
${ }^{1}$ Department of Biological Sciences, Mississippi State University, PO Box GY, Mississippi State, MS 39762.

${ }^{2}$ Department of Entomology, Michigan State University, 288 Farm Ln \#243, East Lansing, MI 48824.

${ }^{3}$ Department of Pathology, University of Michigan, Medical Science Unit I, 1301 Catherine St, Ann Arbor, MI 48109.

${ }^{4}$ Department of Infectious Disease, St. Jude Children's Research Hospital, 262 Danny Thomas Place, Memphis, TN 38105.

${ }^{5}$ Department of Osteopathic Medical Specialties, Michigan State University, West Fee Hall, 909 Fee Road, East Lansing, MI 48824.

Corresponding author: Heather R. Jordan, Ph.D. E-mail: jordan@biology.msstate.edu

Opinions or points of view expressed represent a consensus of the authors and do not necessarily represent the official position or policies of the U.S. Department of Justice.

Funding was provided by Mississippi State University and the National Institute of Justice (2014-DN-BX-K008).

${ }^{\S}$ All demultiplexed raw sequence reads are available on the NCBI Sequence Read Archive (SRP158449) through BioProject (PRJNA486521).

Received 22 Feb. 2019; and in revised form 10 April 2019; accepted 25 April 2019.
}

manner. Such evidence in court is key to convict the guilty, protect the innocent, and unlock circumstances surrounding the death and/or crime so that justice may be upheld. Therefore, there is a forensically relevant need to implement consistent methodologies resulting in data that yield accurate, rapid, and cost-efficient results regardless of potential confounders.

Due to next-generation sequencing, the use of microbial communities in forensic science is an increasingly expanding field. Applications of microbial community sequencing data as are now viewed as a next frontier in forensic science with potential to provide objective, reproducible evidence of cause, time, and manner of death for adjudication by the criminal justice system (6-8). Furthermore, the use of innovative approaches to analyze microbes at the genome, transcript, and protein level has exciting potential for accuracy and consistency in data analysis of microbial samples. Research has shown applicable microbial community contributions to trace evidence, biocrimes, and manner of death (1,9-15). Additionally, a literature review revealed a number of studies detailing predictable microbial successional patterns and human tissue gene expression changes associated with stages of human decomposition $(7,16-21)$.

The majority of these forensic studies have included both animal and human models with exposure to the outside environment, including natural shifts of multiple biotic and abiotic factors. This environmental addition is important since forensic investigations rarely encounter bodies discovered in sterile, controlled environments. Although it is known that changes in environmental factors, such as temperature and humidity, can have drastic effects on the progress of decomposition, it may be difficult to determine which factor(s) has what effect. For 
this reason, we created a controlled model system to determine the baseline decomposition community turnover solely taking place in and on the body. This model allows researchers to add environmental factors and study the subsequent effects on decomposition that occur in reference to the baseline conditions. As more models are established, researchers and investigators can work in unison to create a database of models that account for varying conditions in which a body can be discovered.

We have established a murine model containing normal, healthy murine microflora within an immunocompetent host with the inclusion of two known contributors to the human decomposition process (Staphylococcus aureus and Clostridium perfringens) (22-24). These two bacterial species have been found in mice and shown to colonize living humans, albeit in separate niches, and have been shown to translocate and produce enzymes that break down tissues during decomposition. Additionally, mouse models have shown to contain microbial trends similar in human decomposition and provide an opportunity to easily obtain statistically relevant study sizes along with controlled laboratory conditions $(6,25,26)$. We describe here the colonization of mice orally with chromosomally tagged red fluorescent $S$. aureus and nonfluorescent plasmid tagged $C$. perfringens. We sequenced total RNA from multiple organs to monitor both the microbial community and functional changes from a single sample. We show that both microbial mRNA and rRNA can be successfully extracted and separated computationally from total RNA to allow for both structural and functional analyses. These data are comparable to performing $16 \mathrm{~S}$ rRNA and RNA-Seq individually and are more cost effective as only one sequencing run is necessary.

Further, we are among the first to utilize postmortem microbial metatranscriptomic analyses, determining both community structure and function from single samples. However, it is important to note that multiple studies have shown functional potential is predicted to change with the PMI or have focused on select sole-carbon source utilization, even fewer studies have studied the full microbial functional profile of RNA transcripts $(1,6,7,26)$. Until recently, postmortem transcriptome analyses have focused on the host transcriptome changes instead of the bacterial communities associated with the host. Metagenomic data provide valuable insights about microbial community structure and can predict functional potential $(20,27)$. Metatranscriptomic data have the advantage to reveal the true functional potential by directly measuring the RNA transcripts produced within the microbial community at a specific time and place, along with providing information on which species are present. In the context of forensics, metatranscriptomics from a single sample will aid in determining postmortem microbiome changes observed during decomposition succession, or the PMI, which may mediate individual microbiome plasticity. Data have shown that generalist microbes within a community, though taxonomically distinct, can encode genes for the same metabolic functions, which may blur the association between community composition and ecosystem functioning, and while individual similar ecosystems may contain different communities, the functional profiles will be similar (28). This functional similarity across similar ecosystems raises the question whether functional redundancy is found between living hosts who have been shown to carry distinct microbiomes. However, functions performed by only a few taxa may closely follow changes in the abundance of those taxa, particularly for more narrow functions, such as with degradation of toxic compounds or of other, specific recalcitrant compounds $(28,29)$. Additionally, microbes may have dissimilar functional roles during decomposition than they had on the living host that might be obscured while analyzing functional potential from metagenomic data. Though if functional redundancy existing during the decomposition processes, measuring the functional profiles at different PMIs may provide a way to reduce the impact of personalized human microbiomes. Understanding mechanisms by which active members of the community respond to environmental disturbance including shifts in community composition, gene expression patterns, or density will benefit studies in decomposition ecology and forensic science and will aid in biomarker discovery for PMI estimation.

\section{Materials and Methods}

Staphylococcus aureus KUB7/C. perfringens + pZMB2 Creation

Detailed description on the construction of Staphylococcus aureus KUB7 can be found in Burcham et al. 2016 (1), and an experimental procedure flowchart is included in Fig. 1. S. aureus KUB7 is a constructed strain that constitutively expresses a red fluorescent protein (RFP). C. perfringens type A strain WAL 14572 was obtained from ATCC. The vector pGLOW-C-Bs2 which contains the evoglow-Bs2 cyan fluorescent protein gene (CFP) was obtained from Jena Bioscience. To create a constitutively expressed vector, $C$. perfringens DNA was extracted using a modified protocol of that discussed in Williamson et al. (30). The per-fdx promoter was amplified out, and EcoR1 and Sac1 restriction sites were added at the $5^{\prime}$ of the forward and reverse strands, respectively, using the following PCR parameters: $3 \mathrm{~m}-95^{\circ} \mathrm{C}$, $\left(30 \mathrm{sec}-95^{\circ} \mathrm{C}, 30 \mathrm{sec}-58^{\circ} \mathrm{C}, 30 \mathrm{sec}-72^{\circ} \mathrm{C}\right) \times 39,5 \mathrm{~m}-$ $72^{\circ} \mathrm{C}$. The promoter is a ferredoxin gene-based promoter primer sequences obtained from Takamizawa et al. (31) (forward: (5'-CG[GAATTC]TAGGCTAAATATGCTTAAAAGAG-3') and reverse: (5'-GG[GAGCTC]ATATTTATATTATCATATTTTTG CTAA- $\left.3^{\prime}\right)$ ). Both the amplicon and pGLOW-Bs2 were sequentially digested with EcoR1 then Sac1; then, the digested amplicon and vector were ligated using T4 DNA ligase. Digestion and ligation were performed with New England BioLabs ${ }^{\circledR}$ $\left(\mathrm{NEB}^{\circledR}\right)$ enzymes following standard manufacturer protocol. The newly created vector was chemically transformed using $\mathrm{NEB}^{\circledR}$ 5-alpha Competent Escherichia coli (High Efficiency) following manufacturer protocol.

Transformants were confirmed with colony PCR using per-fdx promoter detection and stored at $-80^{\circ} \mathrm{C}$ until the pGLOW-Bs2$\mathrm{fdx}$ vector was isolated using the QIAGEN $^{\circledR}$ Plasmid DNA Maxiprep kit. We had difficulty transforming pGLOW-Bs2-fdx into $C$. perfringens; therefore, we amplified the per-fdx promoter and CFP gene out of the vector and added a Xho1 cut site on the $5^{\prime}$ forward with the primers (forward: (5'-GC[CTCGAG] TACGAATTCTAGGCTAAAT-3') and reverse: (5'-GCAGGTCGACTCTAGAGGATCCTTA- $\left.3^{\prime}\right)$ ). The amplified product and new vector pJIR750 obtained from ATCC were double digested with EcoR1-HF and Xba1 enzymes obtained from NEB ${ }^{\circledR}$, and completed digests were ligated together using T4 DNA ligase. A Kpn1 $\mathrm{NEB}^{\circledR}$ enzyme digest was performed on the ligation to vector kill any plasmids that did not obtain the PCR product since insertion of the product interrupts the Kpn1 cut site only nonligated vectors will contain the cut site. Afterward, the newly created vector (pZMB2) was cleaned using the QIAGEN ${ }^{\circledR}$ DNeasy PowerClean Pro Clean-Up kit and resuspended in $30 \mu \mathrm{L}$ nuclease-free water. 


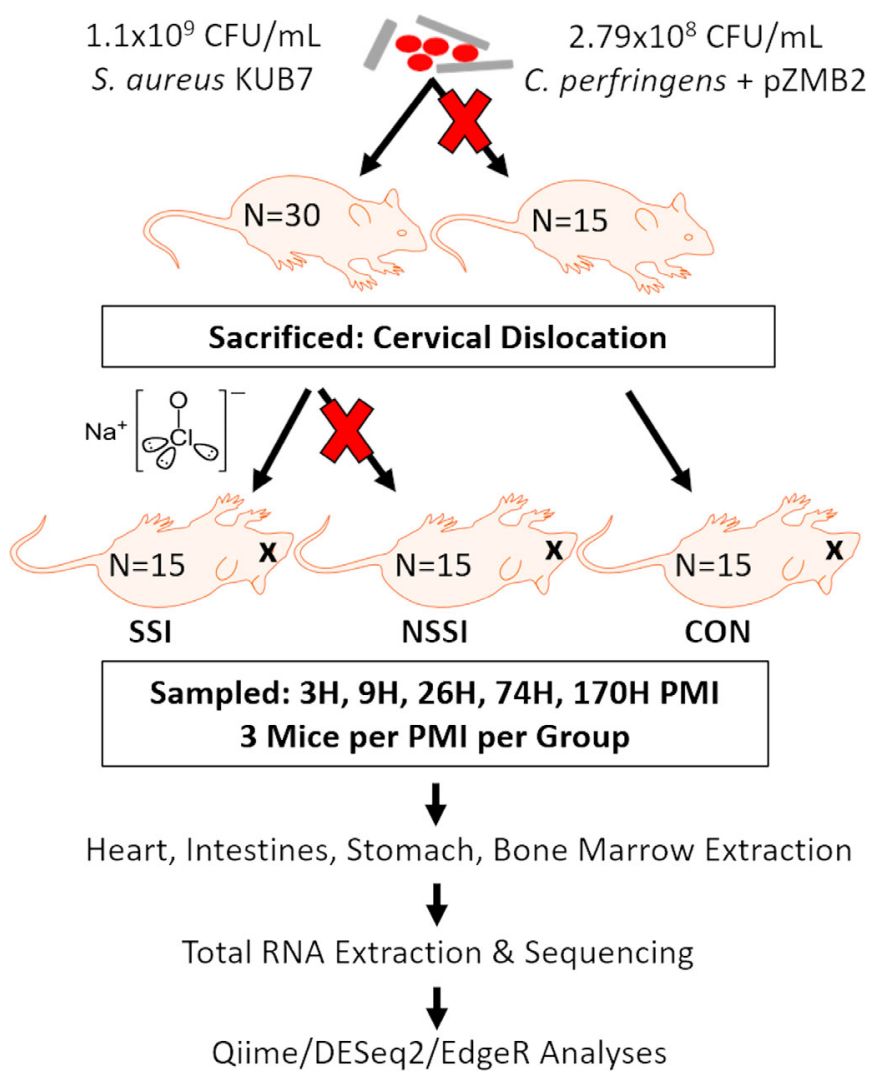

FIG. 1-Experimental flow chart. A visual representation of the experimental design and downstream analyses. Mouse groups are represented as SSI = surface sterilized, colonized; NSSI = nonsurface sterilized, colonized $;$ and $C O N=$ control . [Color figure can be viewed at wileyonlinelibrary.com]

Exponential decay electroporation was performed using $1 \mu \mathrm{L}$ vector and $25 \mu \mathrm{L} \mathrm{NEB}{ }^{\circledR}$ 5-alpha Electrocompetent $E$. coli in $1 \mathrm{mM}$ cuvette on the Bio-Rad Gene Pulser Xcell ${ }^{\mathrm{TM}}$ using the settings: $1800 \mathrm{~V}, 25 \mu \mathrm{F}$, and $200 \Omega$. Transformants were confirmed with colony PCR using per-fdx promoter detection and stored at $-80^{\circ} \mathrm{C}$. Electrocompetent $C$. perfringens was created by growing $5 \mathrm{~mL}$ anaerobically overnight in Luria Broth (LB). The next day, the overnight culture was added to $50 \mathrm{~mL}$ fresh $\mathrm{LB}$ and incubated at $37^{\circ} \mathrm{C}$ for $2.5 \mathrm{~h}$. The culture was spun down at $12,000 \times g$ for $10 \mathrm{~m}$ at $4^{\circ} \mathrm{C}$, washed with $5 \mathrm{~mL}$ of sucrose-magnesium-phosphate (SMP) buffer, spun down, resuspended in $1 \mathrm{~mL}$ SMP buffer, aliquoted into $100 \mu \mathrm{L}$ tubes, and stored at $-80^{\circ} \mathrm{C}$. C. perfringens exponential decay electroporation was set up using $1 \mu \mathrm{g}$ pZMB2 and $50 \mu \mathrm{L}$ of electrocompetent $C$. perfringens in a $1 \mathrm{mM}$ cuvette in a Bio-Rad Gene Pulser Xcell ${ }^{\mathrm{TM}}$ using the settings: $625 \mathrm{~V}, 25 \mu \mathrm{F}$, and $200 \Omega$. The sample was immediately transferred to $1 \mathrm{~mL}$ of $37^{\circ} \mathrm{C}$ SOC medium (Thermo Fisher Scientific, Waltham, MA, USA) and let recover anaerobically for $3 \mathrm{~h}$ at $37^{\circ} \mathrm{C}$. Afterward, $100 \mu \mathrm{L}$ was plated on LB agar supplemented with Chloramphenicol $(20 \mu \mathrm{g} / \mathrm{mL})$ and left to incubate overnight anaerobically at $37^{\circ} \mathrm{C}$. Transformants were confirmed for $\mathrm{pZMB} 2$ using colony $\mathrm{PCR}$, and positive samples were stored at $-80^{\circ} \mathrm{C}$. C. perfringens + pZMB2 transformants were detectable through qPCR, but failed to produce detectable fluorescence.

\section{Inoculum Preparation and Murine Inoculation}

Staphylococcus aureus KUB7 and C. perfrigens + pZMB2 were grown overnight in $3 \mathrm{~mL} \mathrm{LB}$ aerobically and anaerobically, respectively. The next morning, each $3 \mathrm{~mL}$ overnight culture was added to fresh $100 \mathrm{~mL}$ LB. S. aureus KUB7 was grown aerobically to $\mathrm{OD}_{600}$ of 0.5 , and $C$. perfringens + pZMB2 was grown anaerobically to $\mathrm{OD}_{600}$ of 0.35 . S. aureus KUB7 and $C$. perfrigens + pZMB2 were aliquoted to $641-\mathrm{mL}$ microcentrifuge tubes and pelleted to remove supernatant. The $S$. aureus KUB7 pellet was resuspended in $100 \mu \mathrm{L}$ phosphate-buffered saline (PBS); then, the resuspension was used to resuspend $C$. perfrigens + pZMB2 to create a single co-inoculum. The inoculum was brought up to $600 \mu \mathrm{L}$ with PBS. The inoculum colonyforming units per $\mathrm{mL}(\mathrm{CFU} / \mathrm{mL})$ count were calculated, and the inoculum was diluted to obtain counts in colonization range. The final inoculums contained $1.1 \times 10^{9} \mathrm{CFU} / \mathrm{mL} S$. aureus KUB7 and $2.49 \times 10^{8} \mathrm{CFU} / \mathrm{mL} C$. perfrigens + pZMB2. Thirty isoflurane-sedated SKH-1 female mice $(N=30)$ obtained from Charles Rivers Laboratories were given $100 \mu \mathrm{L}$ of the co-inoculum through oral gavage, and 15 mice were given $100 \mu \mathrm{L}$ PBS with as controls $(N=15)$ for a total of 45 mice $(N=45)$. Mice were housed based on their randomly chosen postmortem timepoint for dissection with no more than five mice per housing. All animal experiments were conducted in July 2017. This study was carried out in accordance with the principles of the Basel Declaration and recommendations of the Mississippi State University Institutional Animal Care and Use Committee Protocol 14-102 and Biosafety Committee Protocol 009-14. The study was approved by the Mississippi State University Institutional Animal Care and Use Committee.

\section{Murine Sacrifice, Controlled Decomposition, and Organ Harvest}

Twenty-four hours after inoculation, all mice were sacrificed by cervical dislocation, as previously described (1). Fifteen of the 30 inoculated mice $(N=15)$ were randomly chosen to be surface sterilized to disrupt the skin microbial communities. The surface sterilized mice were submerged to below the mouth in a $10 \%$ bleach solution for $45 \mathrm{sec}$ to avoid sterilization of the mouth, nares, and ears and prevent the bleach solution from entering the body. The bleach solution was rinsed with distilled water twice. All 45 mice $(N=45)$ were individually placed in a Nalgene bottle top $0.2 \mu \mathrm{M}$ filter container (Thermo Fisher Scientific) and sealed with Parafilm $\mathrm{M}$ to prevent environmental microbial and insect contamination. Mouse carcasses were allowed to naturally decompose within a bilaminar flow hood at ambient room temperature for up to $170 \mathrm{~h}$ (approx. 7 days) in July 2017 in Starkville, Mississippi, USA.

Three mice per treatment (control, inoculated with no surface sterilization, and inoculated with surface sterilization, $N=9$ total) were analyzed per timepoint $(T=3,9,26,74$, and $170 \mathrm{~h}$ postmortem). All tissue harvesting and subsequent analyses were performed in a bilaminar flow hood under BSL2 and sterile conditions, as previously described (1). A sterile scalpel blade was used to cut through the right hind leg and femur. The separated leg was used to obtain bone marrow from the femur using a sterile syringe containing nuclease-free water. A second sterile scalpel blade was used to dissect each mouse from the ventral side to remove the stomach, heart, and composite of the intestines using sterile forceps, individual for each organ. The bone marrow solution and each organ were transferred to individual 2.0-mL screw cap tubes. Each organ was crushed with a sterile cotton swab excluding the bone marrow solution. Afterward, RNAlater (Thermo Fisher Scientific) was added to each tube and the samples were stored in $-20^{\circ} \mathrm{C}$ until nucleic acid extraction. 


\section{Total RNA Extraction and Purification}

Total RNA extraction using the TRIzol Reagent (Thermo Fisher Scientific) with standard issued protocol was performed on the preserved samples after being spun down and the RNAlater (Ambion) removed. Briefly, $100 \mathrm{mg}$ of tissue or the pelleted bone marrow was added to $1 \mathrm{~mL}$ of TRIzol Reagent (Thermo Fisher Scientific) and a mix of $0.1 / 0.5 \mathrm{~mm}$ glass beads. The samples were homogenized in a bead beater with phase separation following chloroform addition. RNA was precipitated with isopropanol, washed with $75 \%$ ethanol, resuspended in $50 \mu \mathrm{L}$ of nuclease-free water, and incubated at $60^{\circ} \mathrm{C}$ for $15 \mathrm{~min}$. The samples were purified using the PowerClean Pro RNA Clean-Up Kit (Qiagen, Hilden, Germany), quantified fluorometrically using a Qubit 2.0 (Invitrogen, Carlsbad, CA, USA), and then stored at $-80^{\circ} \mathrm{C}$.

\section{Total RNA Library Preparation, Shotgun Sequencing, and Processing}

Total RNA libraries were created using the NEBNext Ultra ${ }^{\mathrm{TM}}$ RNA Library Prep Kit and NEBNext Multiplex Oligos (Dual Index Primers) for Illumina (New England BioLabs) protocols for use with purified mRNA or rRNA depleted RNA on the surface sterilized $(N=20)$, nonsurface sterilized $(N=20)$, and control $(N=20)$ samples. These protocols were chosen to maintain rRNA and mRNA within the RNA sample in order to preserve 16S rRNA transcripts and mRNA transcripts for both structural and differential transcript expression analyses. High-throughput total RNA sequencing was performed by St. Jude Children's Research Hospital on an Illumina HiSeq2000 with $2 \times 100$ bp PE (paired-end) read lengths. Sequences were initially trimmed by the sequencing facility using TrimGlare v0.4.2 (32,33), but a more stringent quality trimming was also performed using Trimmomatic v0.33 (34). Sequences were input in the SAMSA2 pipeline (34). SAMSA2 was used to merge the paired-end sequences with PEAR v0.9.10 (35) and then trimmed in a four-position sliding window with an average phred33 score less than 20, and read lengths less than 99 bp with Trimmomatic v0.36 (33). SortMeRNA v2.1 (36) was used to extract bacteria 16S rRNA transcripts and limit archaea 16S/23S rRNA transcripts and eukaryotic 18S/28S/5S/5.8S rRNA transcripts based on the documentation recommended SILVA and Rfam databases (37). The remaining $16 \mathrm{~S}$ rRNA transcripts were used for community structure analyses, and the rRNA depleted RNA was used for differential expression analyses. Sample identifiers and metadata are shown in Table 1.

\section{S rRNA Community Analysis}

Community structure was determined using QIIME 22018.4 (https://qiime2.org) (38). The reads were truncated to a maximum length of $180 \mathrm{bp}$ and denoised to remove sequencing errors and chimeras with DADA2 (39). To generate a phylogenetic tree for diversity analyses, we first performed a multiple sequence alignment using MAFFT then mask the alignment to remove highly variable regions $(40,41)$. An unrooted tree was created from the masked alignment with FastTree 2 (42). We applied midpoint rooting at the midpoint of the longest tip-to-tip distance. Taxonomic identification was performed using VSEARCH consensus taxonomy classifier using the SILVA 132 QIIME release 99\% majority 16S rRNA only reads with 7 level taxonomy (37,43-45). Any classified reads that had a frequency less than 10 or classified belonging to mitochondria or chloroplast were discarded. The relative abundances of the bacterial families present were determined for each sample with any family present less than $3 \%$ in a sample being considered rare taxa. Alpha and beta diversity analyses performed on the classified OTUs at a sampling depth of 900 reads per sample with metadata included in the analyses: treatment, organ, and postmortem time. Shannon alpha diversity was calculated and compared against metadata using pairwise Kruskal-Wallis. We calculated both weighted and unweighted UniFrac distances (beta diversity) then compared them against the metadata using pairwise permutational multivariate analysis of variance (PERMANOVA; permutations =999). The weighted and unweighted UniFrac distances were used to create principal coordinate analysis (PCoA) plots. UniFrac distances incorporate phylogenetic relationships while weighted distances take into account the bacterial abundances and unweighted treats data as presence-absence (46). Analysis of composition of microbiomes (ANCOM) was performed to identity taxonomic families in each organ that is differentially abundant across postmortem time (47). Statistical significance was determined as Benjamini-Hochberg-corrected $p<0.05$.

\section{Transcript Annotation and Differential Expression Analysis}

Ribosomal RNA-depleted RNA transcripts were used in the SAMSA2 pipeline (34). The reads were annotated using the DIAMOND sequence aligner to a database created from the March 2018 NCBI nr-protein database (48). The best protein hit for each read in the sample was aggregated for differential expression analysis using the $\mathrm{R}$ statistical packages edge $\mathrm{R}$ v3.22.3 and DESeq2 v1.20.0 (49-51). Treatments were not differentiated as community analysis showed no difference between colonization nor surface sterilization. In edgeR, the counts per million were computed and transcripts that were not present more than $1 \mathrm{CPM}$ in at least 2 samples were removed to reduce noise. In DESeq2, transcripts that were not present in at least 2 samples with counts above 1 were removed. Normalization by library size was performed based on each package's recommended method. EdgeR dispersion estimations were determined individually per organ with bone marrow and stomach using spline and heart and intestines using bin-spline. DESeq2 dispersions were estimated based on the default settings from the DESeq command. Timepoint groups were as follows: early (3 and $9 \mathrm{~h}$ ), middle (26 and $74 \mathrm{~h})$, and late $(170 \mathrm{~h})$. All models were created with no y-intercept and the postmortem timepoint groups as the variable for each organ. EdgeR models were negative binomial generalized log-linear models (GLM) with quasilikelihood, and DESeq2 models were negative binomial GLMs with likelihood ratio tests between the full and reduced model without timepoints. For both methods, differential expression was tested to contrast the timepoint groups (early vs. middle, middle vs. late, early vs. late) for each organ and significantly differentially expressed transcripts were identified based on a Benjamini-Hochberg-corrected $p$-value $<0.10$ above $1 \log 2$ fold change threshold. Only transcripts determined to be significant by both methods were considered truly significantly expressed to reduce procedural bias. Transcripts were annotated into pathways based on the KEGG and UniProt databases $(52,53)$.

\section{Results}

Staphylococcus aureus KUB7/C. perfringens $+p Z M B 2$ Detection

Colonization of $S$. aureus KUB7 and $C$. perfringens + pZMB2 was only detectable through qPCR measurements of the RFP and 
TABLE 1-Sample metadata

\begin{tabular}{|c|c|c|c|c|c|c|c|c|c|c|}
\hline Sample & Treatment & Colonized & Sterilized & PMI & Organ & \# RNA reads & \# 16S rRNA reads & \# metaRNA reads & \# OTUs & Family richness \\
\hline MS1701 & $\mathrm{C}$ & $\mathrm{N}$ & $\mathrm{N}$ & $3 \mathrm{H}$ & $\mathrm{HT}$ & 493,225 & 23,220 & 67,276 & 1737 & 4 \\
\hline MS1702 & $\mathrm{C}$ & $\mathrm{N}$ & $\mathrm{N}$ & $3 \mathrm{H}$ & $\mathrm{BM}$ & 168,194 & 14,908 & 62,698 & 282 & 1 \\
\hline MS1703 & $\mathrm{C}$ & $\mathrm{N}$ & $\mathrm{N}$ & $3 \mathrm{H}$ & INT & 409,218 & 45,168 & 8601 & 6617 & 9 \\
\hline MS1704 & $\mathrm{C}$ & $\mathrm{N}$ & $\mathrm{N}$ & $3 \mathrm{H}$ & $\mathrm{ST}$ & 752,026 & 51,241 & 20,686 & 712 & 4 \\
\hline MS1705 & $\mathrm{S}$ & $\mathrm{Y}$ & $\mathrm{Y}$ & $3 \mathrm{H}$ & $\mathrm{HT}$ & 505,997 & 18,044 & 118,327 & 1490 & 2 \\
\hline MS1706 & $\mathrm{S}$ & $\mathrm{Y}$ & $\mathrm{Y}$ & $3 \mathrm{H}$ & $\mathrm{BM}$ & 44,183 & 311 & 39,809 & 44 & 0 \\
\hline MS1707 & $\mathrm{S}$ & $\mathrm{Y}$ & $\mathrm{Y}$ & $3 \mathrm{H}$ & INT & 1555,918 & 274,399 & 14,692 & 49,571 & 11 \\
\hline MS1708 & $\mathrm{S}$ & $\mathrm{Y}$ & $\mathrm{Y}$ & $3 \mathrm{H}$ & ST & 544,635 & 26,513 & 15,597 & 930 & 2 \\
\hline MS1709 & NS & $\mathrm{Y}$ & $\mathrm{N}$ & $3 \mathrm{H}$ & $\mathrm{HT}$ & 2874,280 & 128,264 & 568,258 & 1564 & 2 \\
\hline MS1710 & NS & $\mathrm{Y}$ & $\mathrm{N}$ & $3 \mathrm{H}$ & $\mathrm{BM}$ & 330,409 & 26,226 & 38,662 & 1444 & 1 \\
\hline MS1711 & NS & $\mathrm{Y}$ & $\mathrm{N}$ & $3 \mathrm{H}$ & INT & 1013,540 & 72,919 & 15,049 & 4534 & 8 \\
\hline MS1712 & NS & $\mathrm{Y}$ & $\mathrm{N}$ & $3 \mathrm{H}$ & ST & 555,832 & 44,881 & 36,559 & 2862 & 6 \\
\hline MS1713 & $\mathrm{C}$ & $\mathrm{N}$ & $\mathrm{N}$ & $9 \mathrm{H}$ & HT & 1007,421 & 47,110 & 172,875 & 1562 & 3 \\
\hline MS1714 & $\mathrm{C}$ & $\mathrm{N}$ & $\mathrm{N}$ & $9 \mathrm{H}$ & $\mathrm{BM}$ & 554,059 & 26,749 & 23,920 & 1001 & 1 \\
\hline MS1715 & $\mathrm{C}$ & $\mathrm{N}$ & $\mathrm{N}$ & $9 \mathrm{H}$ & INT & 1364,759 & 82,815 & 47,995 & 4009 & 9 \\
\hline MS1716 & $\mathrm{C}$ & $\mathrm{N}$ & $\mathrm{N}$ & $9 \mathrm{H}$ & ST & 1349,461 & 89,773 & 30,585 & 5554 & 7 \\
\hline MS1717 & $\mathrm{S}$ & $\mathrm{Y}$ & $\mathrm{Y}$ & $9 \mathrm{H}$ & $\mathrm{HT}$ & 2994,097 & 106,949 & 1261,310 & 2265 & 3 \\
\hline MS1718 & $\mathrm{S}$ & $\mathrm{Y}$ & $\mathrm{Y}$ & $9 \mathrm{H}$ & BM & 270,149 & 11,019 & 38,578 & 350 & 0 \\
\hline MS1719 & $\mathrm{S}$ & $\mathrm{Y}$ & $\mathrm{Y}$ & $9 \mathrm{H}$ & INT & 1669,023 & 121,927 & 17,763 & 10,981 & 11 \\
\hline MS1720 & $\mathrm{S}$ & $\mathrm{Y}$ & $\mathrm{Y}$ & $9 \mathrm{H}$ & $\mathrm{ST}$ & 796,221 & 47,815 & 12,839 & 1842 & 5 \\
\hline MS1721 & NS & $\mathrm{Y}$ & $\mathrm{N}$ & $9 \mathrm{H}$ & HT & 997,408 & 43,736 & 340,469 & 3440 & 2 \\
\hline MS1722 & NS & $\mathrm{Y}$ & $\mathrm{N}$ & $9 \mathrm{H}$ & BM & 368,213 & 16,852 & 24,838 & 828 & 2 \\
\hline MS1723 & NS & $\mathrm{Y}$ & $\mathrm{N}$ & $9 \mathrm{H}$ & INT & 1071,570 & 81,311 & 19,114 & 7207 & 9 \\
\hline MS1724 & NS & $\mathrm{Y}$ & $\mathrm{N}$ & $9 \mathrm{H}$ & $\mathrm{ST}$ & 1478,496 & 226,807 & 34,465 & 34,759 & 9 \\
\hline MS1725 & $\mathrm{C}$ & $\mathrm{N}$ & $\mathrm{N}$ & $26 \mathrm{H}$ & $\mathrm{HT}$ & 522,628 & 31,038 & 54,628 & 1432 & 4 \\
\hline MS1726 & $\mathrm{C}$ & $\mathrm{N}$ & $\mathrm{N}$ & $26 \mathrm{H}$ & $\mathrm{BM}$ & 629,159 & 36,773 & 19,039 & 1447 & 1 \\
\hline MS1727 & $\mathrm{C}$ & $\mathrm{N}$ & $\mathrm{N}$ & $26 \mathrm{H}$ & INT & 881,212 & 114,781 & 8766 & 23,548 & 9 \\
\hline MS1728 & $\mathrm{C}$ & $\mathrm{N}$ & $\mathrm{N}$ & $26 \mathrm{H}$ & ST & 869,811 & 38,341 & 9664 & 3306 & 7 \\
\hline MS1729 & $\mathrm{S}$ & $\mathrm{Y}$ & $\mathrm{Y}$ & $26 \mathrm{H}$ & HT & 726,539 & 41,970 & 72,905 & 1714 & 3 \\
\hline MS1730 & $\mathrm{S}$ & $\mathrm{Y}$ & $\mathrm{Y}$ & $26 \mathrm{H}$ & $\mathrm{BM}$ & 36,447 & 668 & 27,914 & 69 & 1 \\
\hline MS1731 & $\mathrm{S}$ & $\mathrm{Y}$ & $\mathrm{Y}$ & $26 \mathrm{H}$ & INT & 3994,433 & 470,358 & 23,604 & 100,045 & 16 \\
\hline MS1732 & $\mathrm{S}$ & $\mathrm{Y}$ & $\mathrm{Y}$ & $26 \mathrm{H}$ & $\mathrm{ST}$ & 6187,692 & 220,910 & 30,159 & 17,211 & 6 \\
\hline MS1733 & NS & $\mathrm{Y}$ & $\mathrm{N}$ & $26 \mathrm{H}$ & $\mathrm{HT}$ & 2297,657 & 110,162 & 256,915 & 2702 & 3 \\
\hline MS1734 & NS & $\mathrm{Y}$ & $\mathrm{N}$ & $26 \mathrm{H}$ & $\mathrm{BM}$ & 4823,405 & 276,299 & 73,004 & 17,584 & 3 \\
\hline MS1735 & NS & $\mathrm{Y}$ & $\mathrm{N}$ & $26 \mathrm{H}$ & INT & 4786,442 & 465,240 & 26,406 & 96,805 & 17 \\
\hline MS1736 & NS & $\mathrm{Y}$ & $\mathrm{N}$ & $26 \mathrm{H}$ & ST & 4670,057 & 320,933 & 33,129 & 50,435 & 13 \\
\hline MS1737 & $\mathrm{C}$ & $\mathrm{N}$ & $\mathrm{N}$ & $74 \mathrm{H}$ & HT & 4969,927 & 256,849 & 65,176 & 13,111 & 4 \\
\hline MS1738 & $\mathrm{C}$ & $\mathrm{N}$ & $\mathrm{N}$ & $74 \mathrm{H}$ & $\mathrm{BM}$ & 136,543 & 6652 & 105,586 & 778 & 4 \\
\hline MS1739 & $\mathrm{C}$ & $\mathrm{N}$ & $\mathrm{N}$ & $74 \mathrm{H}$ & INT & 2904,244 & 979,241 & 29,095 & 238,714 & 18 \\
\hline MS1740 & $\mathrm{C}$ & $\mathrm{N}$ & $\mathrm{N}$ & $74 \mathrm{H}$ & ST & 6641,573 & 2513,136 & 192,042 & 352,308 & 15 \\
\hline MS1741 & $\mathrm{S}$ & $\mathrm{Y}$ & $\mathrm{Y}$ & $74 \mathrm{H}$ & $\mathrm{HT}$ & 5245,925 & 233,351 & 70,186 & 11,868 & 4 \\
\hline MS1742 & $\mathrm{S}$ & $\mathrm{Y}$ & $\mathrm{Y}$ & $74 \mathrm{H}$ & $\mathrm{BM}$ & 35,474 & 2566 & 21,921 & 92 & 3 \\
\hline MS1743 & $\mathrm{S}$ & $\mathrm{Y}$ & $\mathrm{Y}$ & $74 \mathrm{H}$ & INT & 4004,065 & 1344,549 & 40,298 & 262,263 & 16 \\
\hline MS1744 & $\mathrm{S}$ & $\mathrm{Y}$ & $\mathrm{Y}$ & $74 \mathrm{H}$ & ST & 115,073 & 14,087 & 41,581 & 938 & 2 \\
\hline MS1745 & NS & $\mathrm{Y}$ & $\mathrm{N}$ & $74 \mathrm{H}$ & $\mathrm{HT}$ & 4775,370 & 203,646 & 69,978 & 10,017 & 7 \\
\hline MS1746 & NS & $\mathrm{Y}$ & $\mathrm{N}$ & $74 \mathrm{H}$ & $\mathrm{BM}$ & 1444,079 & 352,811 & 151,536 & 57,090 & 4 \\
\hline MS1747 & NS & $\mathrm{Y}$ & $\mathrm{N}$ & $74 \mathrm{H}$ & INT & 3705,578 & 1178,971 & 73,858 & 265,751 & 20 \\
\hline MS1748 & NS & $\mathrm{Y}$ & $\mathrm{N}$ & $74 \mathrm{H}$ & ST & 7103,195 & 2384,764 & 349,170 & 323,904 & 18 \\
\hline MS1749 & $\mathrm{C}$ & $\mathrm{N}$ & $\mathrm{N}$ & $170 \mathrm{H}$ & $\mathrm{HT}$ & 8772,565 & 3141,078 & 257,655 & 410,126 & 14 \\
\hline MS1750 & $\mathrm{C}$ & $\mathrm{N}$ & $\mathrm{N}$ & $170 \mathrm{H}$ & $\mathrm{BM}$ & 156,527 & 21,510 & 100,408 & 2780 & 5 \\
\hline MS1751 & $\mathrm{C}$ & $\mathrm{N}$ & $\mathrm{N}$ & $170 \mathrm{H}$ & INT & 7283,554 & 2505,032 & 83,971 & 276,586 & 16 \\
\hline MS1752 & $\mathrm{C}$ & $\mathrm{N}$ & $\mathrm{N}$ & $170 \mathrm{H}$ & ST & 141,268 & 7807 & 110,978 & 713 & 4 \\
\hline MS1753 & $\mathrm{S}$ & $\mathrm{Y}$ & $\mathrm{Y}$ & $170 \mathrm{H}$ & HT & 5683,664 & 2326,728 & 152,434 & 376,453 & 19 \\
\hline MS1754 & $\mathrm{S}$ & $\mathrm{Y}$ & $\mathrm{Y}$ & $170 \mathrm{H}$ & $\mathrm{BM}$ & 77,072 & 3245 & 64,322 & 311 & 4 \\
\hline MS1755 & $\mathrm{S}$ & $\mathrm{Y}$ & $\mathrm{Y}$ & $170 \mathrm{H}$ & INT & 5850,139 & 1625,875 & 50,451 & 75,506 & 18 \\
\hline MS1756 & $\mathrm{S}$ & $\mathrm{Y}$ & $\mathrm{Y}$ & $170 \mathrm{H}$ & ST & 8137,571 & 2932,888 & 97,344 & 316,843 & 13 \\
\hline MS1757 & NS & $\mathrm{Y}$ & $\mathrm{N}$ & $170 \mathrm{H}$ & HT & 5096,086 & 1926,124 & 176,191 & 310,930 & 20 \\
\hline MS1758 & NS & $\mathrm{Y}$ & $\mathrm{N}$ & $170 \mathrm{H}$ & BM & 367,252 & 117,125 & 99,943 & 20,976 & 6 \\
\hline MS1759 & NS & $\mathrm{Y}$ & $\mathrm{N}$ & $170 \mathrm{H}$ & INT & 9671,062 & 3298,364 & 76,833 & 198,896 & 16 \\
\hline MS1760 & NS & $\mathrm{Y}$ & $\mathrm{N}$ & $170 \mathrm{H}$ & ST & 92,826 & 12,663 & 36,897 & 977 & 5 \\
\hline
\end{tabular}

Table demonstrates the sample identification with their treatment $(\mathrm{C}=$ control, $\mathrm{NS}=$ nonsurface sterilized, $\mathrm{S}=$ sterilized $)$, if they were colonized $(\mathrm{Y}=\mathrm{Yes}$,

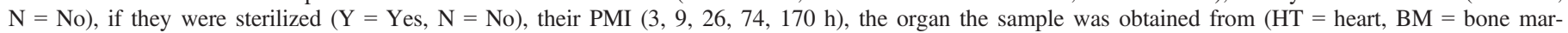

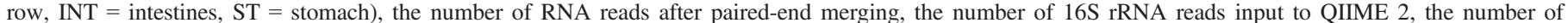
metaRNA reads input in DE analysis, and the family richness of each sample based on 16S rRNA. Read counts are after quality control.

CFP genes (Figures S1-S4). S. aureus KUB7 was essentially absent, apart from a few outliers, in the kidneys, spleen, intestines, stomach, and bone marrow with detection appearing after 3 days in the lungs and liver, 5 days on the skin, and 7 days in the heart. $C$. perfringens + pZMB2 was essentially absent, apart from a few outliers, in all organs except the intestines and one instance of a 14-day heart sample. Introduced species in a previous model were shown to significantly die off past 30 days 
postmortem $(1,26)$. The low colonization abundances and inconsistencies across mice inhibited reliable translocation tracking of S. aureus KUB7 and C. perfringens + pZMB2; therefore, further analyses focused on the bacterial community structural and functional turnover across postmortem time through high-throughput sequencing. A statistical comparison of the bacterial communities of colonized mice against noncolonized mice showed no significant difference allowing for colonization and noncolonization data to be combined for increased sample size and statistical significance.

\section{S rRNA Family Relative Abundance}

In total, 41 families were detected across 60 samples for a total of 3751,013 classifications $(\min =0, \quad \max =1482,222$, mean $=91488.12, \mathrm{SD}=301722.61)$. Two samples were unclassified and both samples belonged to bone marrow early postmortem times ( 3 and $9 \mathrm{~h}$ ). The two most detected families by over 800,000 classifications were Lactobacillaceae $(N=1482,222)$ and Clostridiaceae I $(N=1242,443)$. Twentysix families $(63 \%)$ were found in low abundance across all samples and were grouped into rare taxa. The stomach (Fig. 2A) showed a microbial shift after $26 \mathrm{~h}$ as Ruminococcaceae, Nitrososphaeraceae, and Lachnospiraceae began to decrease in relative abundance with Lactobacillaceae dominating at $74 \mathrm{~h}$ and the introduction of Clostridiaceae I at $170 \mathrm{~h}$ postmortem. The intestines (Fig. 2B) showed a similar trend where samples $\leq 26 \mathrm{~h}$ were dominated by Ruminococcaceae and Lachnospiraceae, followed by a shift to Lactobacillaceae dominance at $74 \mathrm{~h}$, and Clostridiaceae I competing at $170 \mathrm{~h}$. In the heart (Fig. 2C), early postmortem times $(\leq 9 \mathrm{~h})$ were predominately Nitrososphaeraceae. After 26 h, Clostridiaceae I increased and was dominated by Clostridiaceae I by $74 \mathrm{~h}$, along with a small community of Enterobacteriaceae. Bone marrow (Fig. 2D) samples $\leq 26 \mathrm{~h}$ were predominately Nitrososphaeraceae with the exception of MS1730 where only Deferribacteraceae was detected. Lactobacillaceae was detected in high abundance at $74 \mathrm{~h}$, and Clostridiaceae I and Clostridiales Family XI were dominant $170 \mathrm{~h}$ postmortem.

\section{S rRNA Community Diversity}

Comparing Shannon diversity indices as grouped by the metadata factors showed that only the organ in which the sample originated had an effect, rather than the postmortem time or treatment $\left(H=23.46, q=3.24 \times 10^{-5}\right)$. The bone marrow $(H=11.69$, $\left.q=1.89 \times 10^{-3}\right)$, heart $\left(H=18.43, q=1.06 \times 10^{-4}\right)$, and stomach $\left(H=8.83, q=5.93 \times 10^{-3}\right)$ all had significantly smaller Shannon diversity indices when compared to the intestines (Fig. 3). When analyzing the Shannon diversity differences by postmortem time in each individual organ tissue, the overall Kruskal-Wallis model determined the heart $(H=11.20$, $\left.p=2.44 \times 10^{-2}\right)$ and intestines $\left(H=9.70, p=4.48 \times 10^{-2}\right)$ to have significant changes, and pairwise comparison of the timepoints did not determine any specific postmortem times to be significantly different. Though individual tissue assessment is possible, it is important to keep in mind that each timepoint only has at most three mice which may affect the ability to detect significant effects. Beta diversity comparisons with PERMANOVA showed a significant difference in weighted UniFrac distances
A.

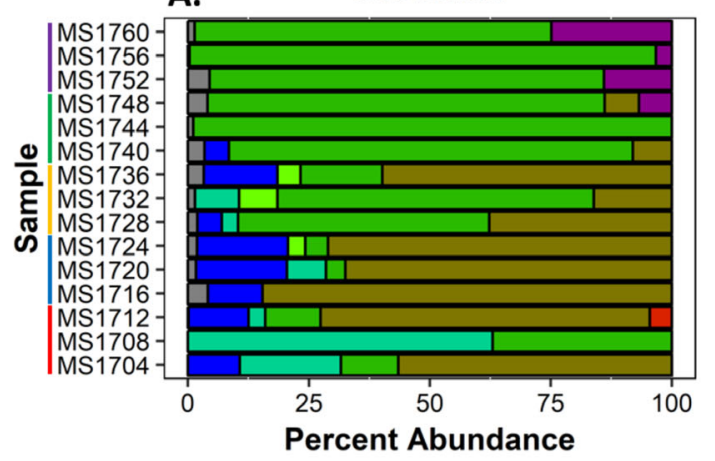

C.

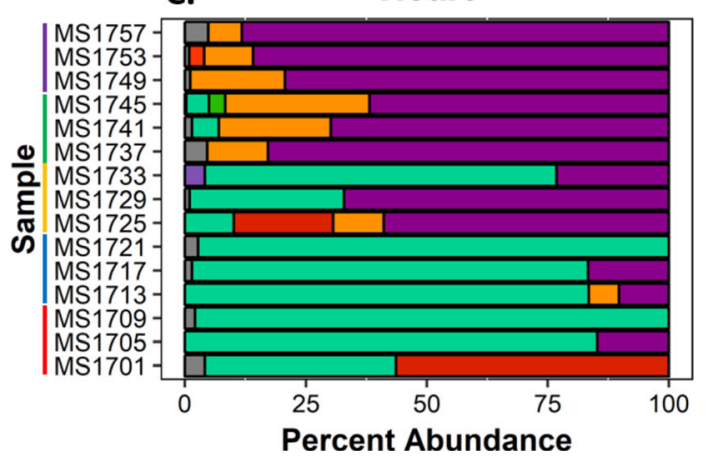

B.

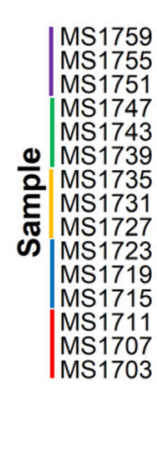

D.

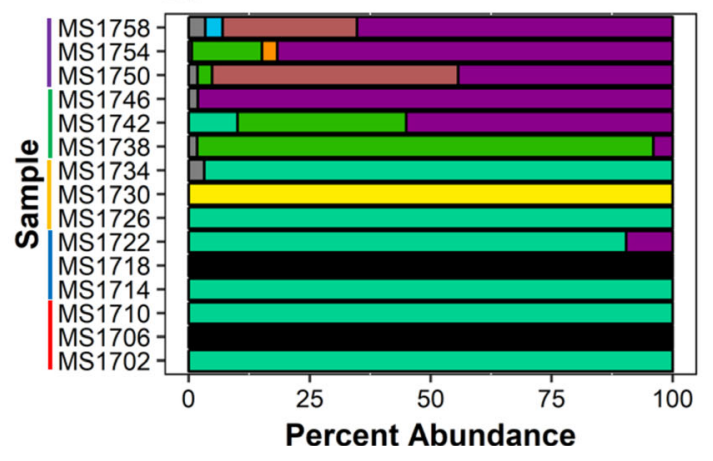

Intestines

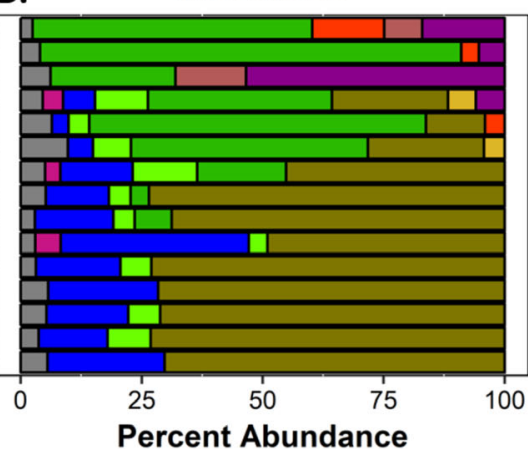

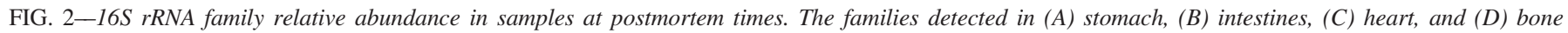

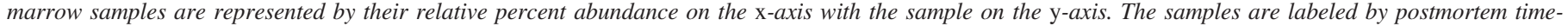

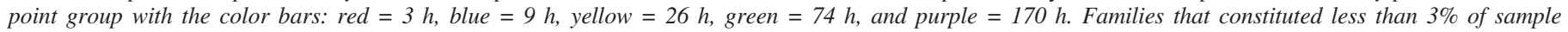

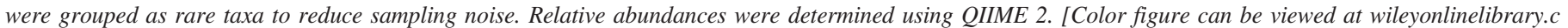
om] 


\section{Shannon Diversity across Organs}

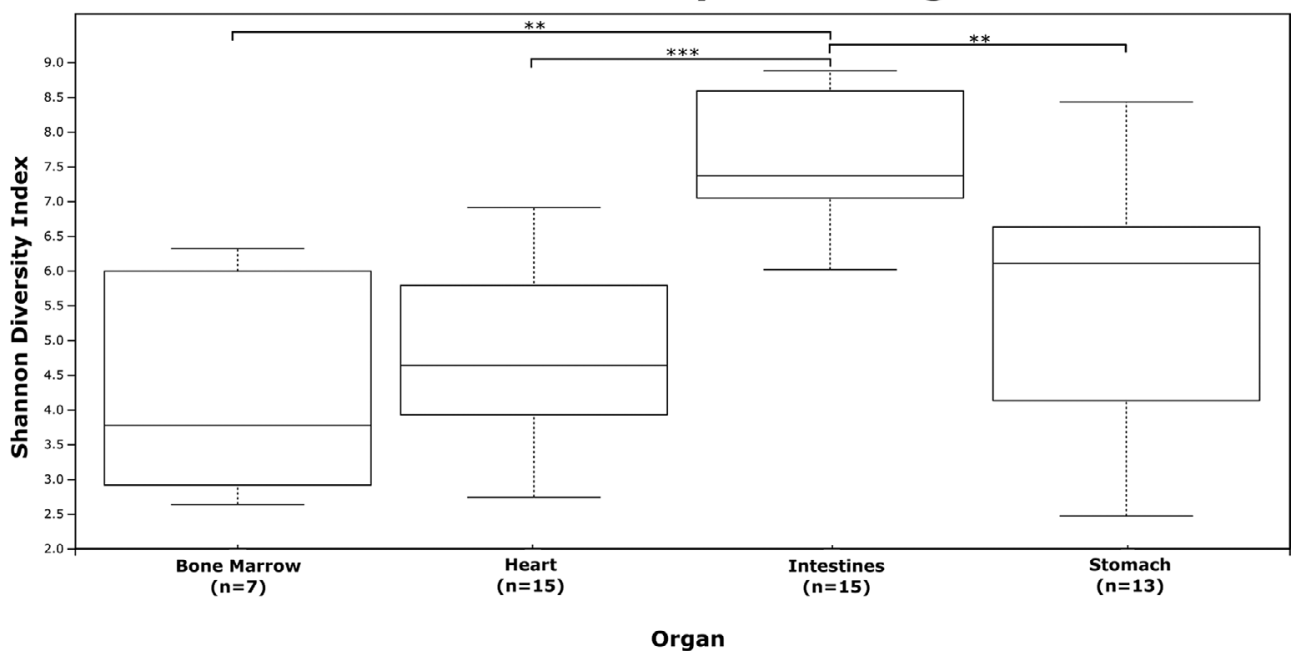

FIG. 3-Alpha diversity comparisons between organs. Boxplots representing the pairwise Kruskal-Wallis comparisons of Shannon diversity indices across organs. Analysis was performed in QIIME 2, and significance levels are as follows: $* \mathrm{p} \leq 0.05, * * \mathrm{p} \leq 0.01, * * * \mathrm{p} \leq 0.001$.

between organ (pseudo- $F=4.32, p=1 \times 10^{-3}, k=4, N=50$ ) and postmortem time (pseudo- $F=5.94, p=1 \times 10^{-3}, k=5$, $N=50$ ) (Fig. 4A,B).

Pairwise analyses for weighted and unweighted UniFrac organ and postmortem time comparisons are shown in Table S1. Weighted UniFrac distance comparison to the intestines (Fig. 4A) showed that the intestines mean beta diversity was different from bone marrow and heart while the stomach microbial diversity was only different from biodiversity in the heart. The stomach and intestines tended to score similarly while also the heart and bone marrow tended to score similarly. Comparison of weighted UniFrac distance by postmortem times (Fig. 4B) showed that the first $26 \mathrm{~h}$ were similar, with separation at $74 \mathrm{~h}$ from the $\leq 26 \mathrm{~h}$ timepoints, and further separation at $170 \mathrm{~h}$.

Beta diversity comparisons showed a significant difference in unweighted UniFrac distances between organ (pseudo- $F=4.4$, $p=1 \times 10^{-3}, k=4, N=50$ ) and postmortem time (pseudo$F=3.63, p=1 \times 10^{-3}, k=5, N=50$; Fig. 4C,D). Interestingly, performing the same comparisons using the unweighted UniFrac distances determined that more significant differences existed between both organ and postmortem times. Unweighted UniFrac distance comparisons by organ (Fig. 4C) returned significant differences between the intestines and all other organs along with differences between the stomach and heart as well as stomach and bone marrow. As with the weighted UniFrac distances, the bone marrow and heart scored similarly with unweighted distances. Unweighted UniFrac comparison between postmortem times (Fig. 4D) showed no difference during the first $26 \mathrm{~h}$, a separation at $76 \mathrm{~h}$, and further separation at $170 \mathrm{~h}$. However, in contrast to the weighted analysis, the unweighted analysis determined a significant difference between 76 and $170 \mathrm{~h}$. It is important to note that treatment conditions such as colonization of $S$. aureus and $C$. perfringens along with surface sterilization did not cause significant differentiation between the microbial communities. Since these treatments were not significant in any of the diversity analyses, the treatments were no longer differentiated in community analysis, PCoA visualization, or differential expression analysis allowing for the data across treatments to be combined for greater sample size and statistical significance.
Visualization of the weighted and unweighted UniFrac distances with a PCoA (Fig. 5) showed that the heart and bone marrow, then intestines and stomach tended to group closely, suggesting the similarity found in the pairwise comparisons. In the weighted UniFrac PCoA (Fig. 5A), the $\leq 26 \mathrm{~h}$ heart and bone marrow all clustered closely and the $\leq 26 \mathrm{~h}$ intestines clustered together but separate from the heart and bone marrow. Interestingly, the $\leq 26 \mathrm{~h}$ stomach samples had a larger variability between them, but continued to stay in the range of the other $\leq 26 \mathrm{~h}$ timepoints. As decomposition progressed to $170 \mathrm{~h}$ postmortem, the intestines and stomach became similar, likely due to the samples being dominated by Lactobacillaceae and the heart and bone marrow likely became similar with the increase in Clostridiaceae I. Samples primarily moved along the axis 1 as decomposition progressed which shows that time since death explains up to $49 \%$ of the bacterial community variation. The heart and bone marrow moved the furthest distance on axis 1, suggesting their communities had the most turnover across the PMI. The unweighted UniFrac PCoA (Fig. $5 B)$ again showed early $(\leq 26 \mathrm{~h})$ communities in the heart and bone marrow to be similar but unique from early intestines and stomach with the exception of one 3-h stomach sample. As decomposition progressed, both clusters moved across axis $1(27 \%)$ and axis $2(17 \%)$ until converging. The intestines and stomach communities transitioned in a "step-like" pattern while the heart and bone marrow transitioned rapidly at $74 \mathrm{~h}$. ANCOM determined the differentially abundant taxa over the course of decomposition to be Lactobacillaceae $(W=9)$ and Clostridiaceae $\mathrm{I}(W=8)$ in the bone marrow; Lactobacillaceae $(W=42)$, Clostridiaceae I $(W=42)$, and Enterobacteriaceae $(W=40)$ in the heart; Lactobacillaceae $(W=47)$, Enterococcaceae $(W=43)$, and Clostridiales Family $\mathrm{XI}(W=41)$ in the intestines; and Clostridiaceae I $(W=47)$ in the stomach.

\section{Transcriptome Differential Expression}

The edgeR mean transcript library size after filtering for the intestines was $8760.4(\min =1138, \max =34,656, \mathrm{SD}=8760.4)$, heart was $34,171(\min =5717, \max =116,326, \mathrm{SD}=36751.99)$, 
A

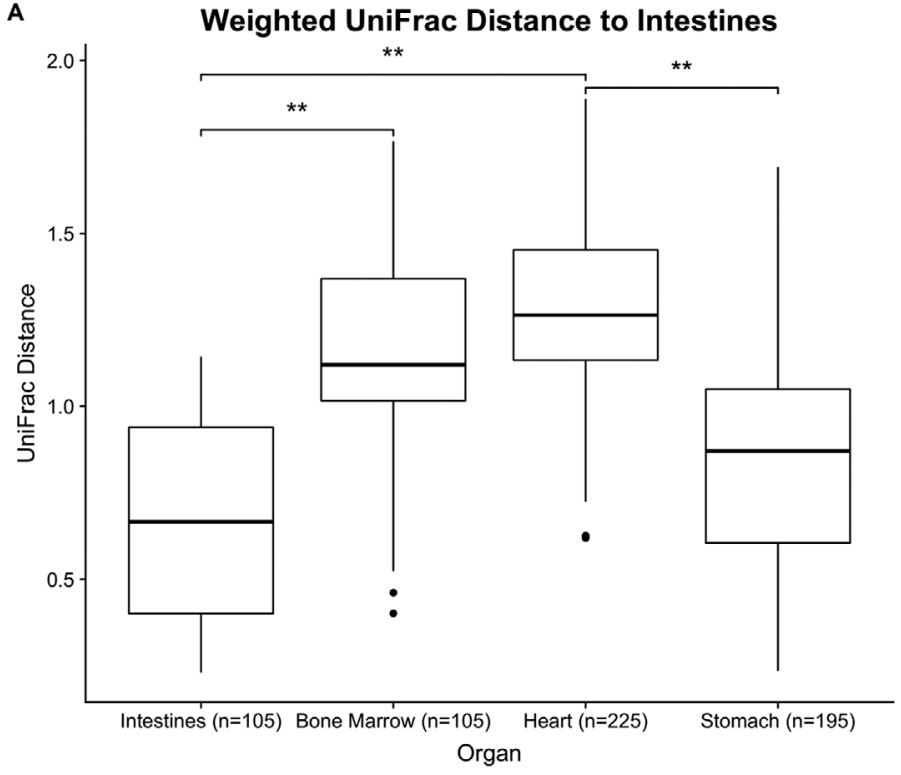

C

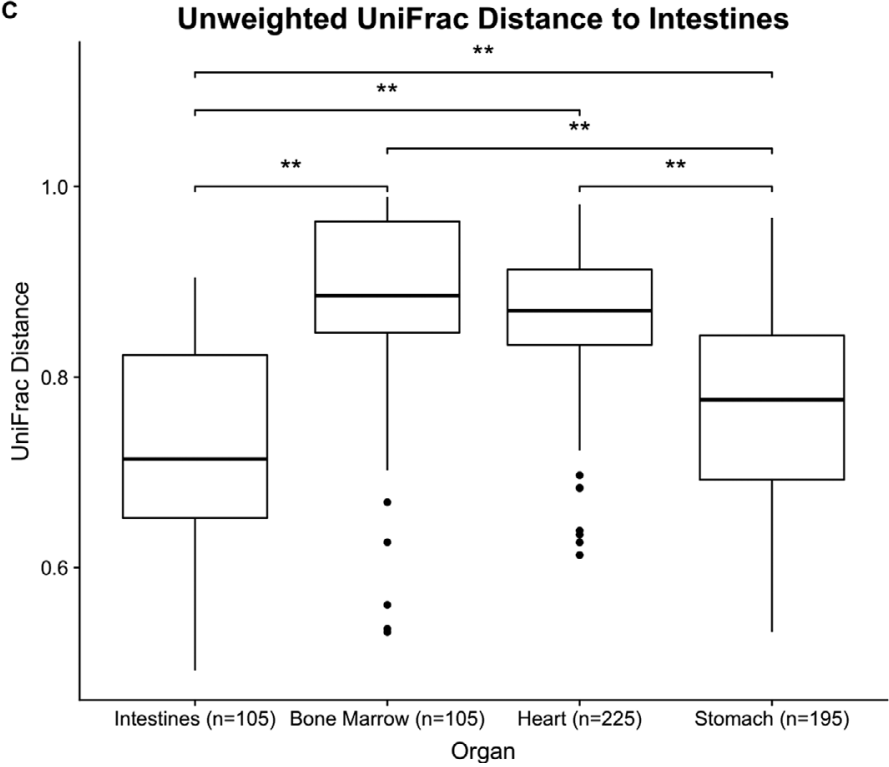

B

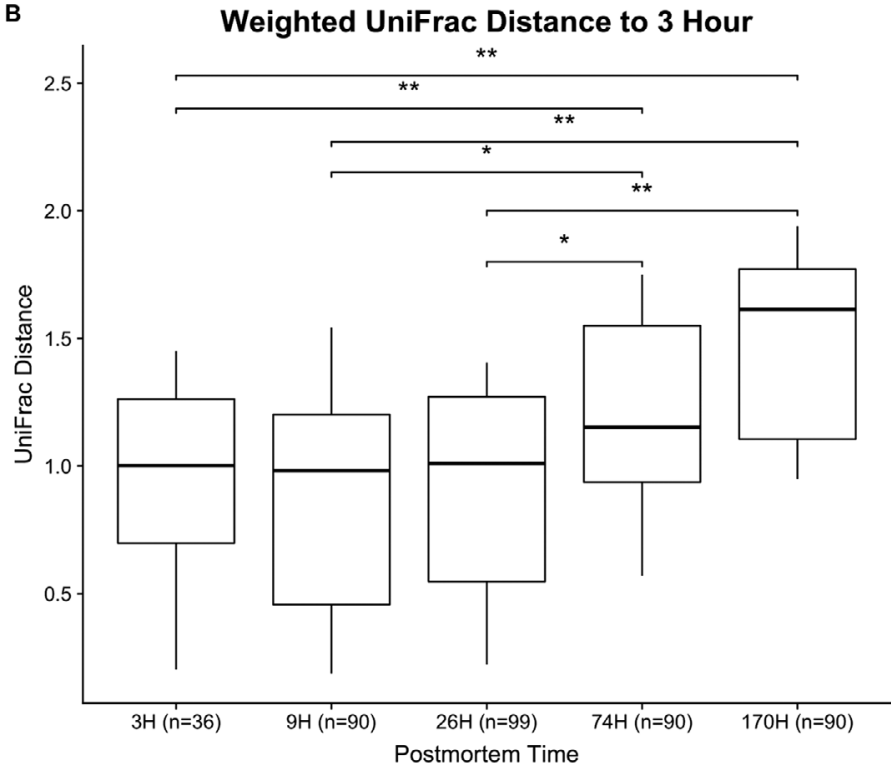

D

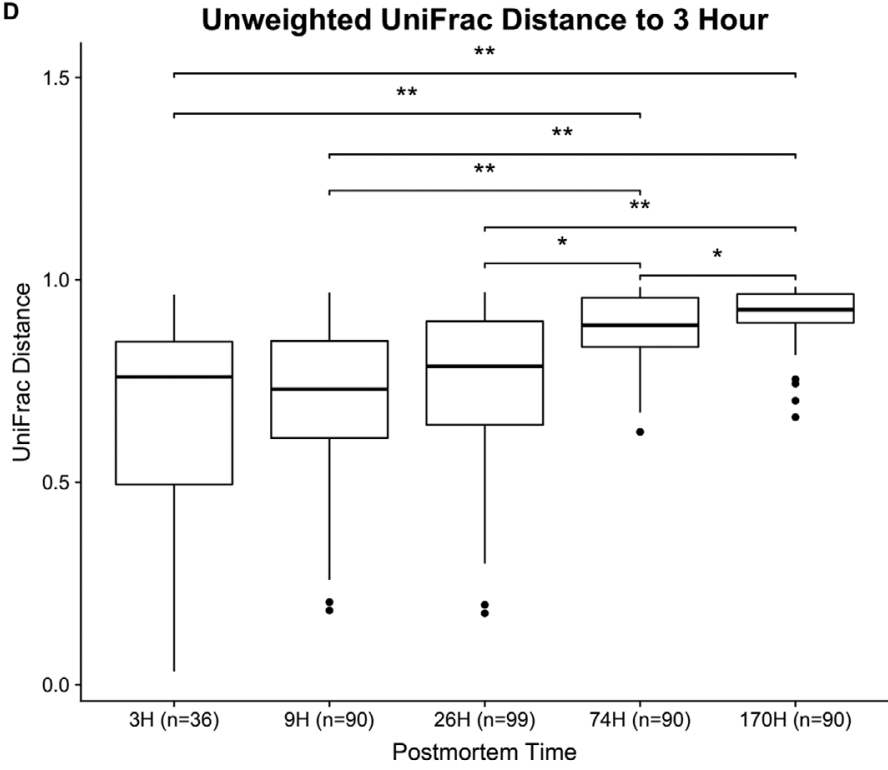

FIG. 4-Beta diversity comparisons between postmortem times and organs. Boxplots representing the PERMANOVA comparisons of weighted UniFrac distances across $(A)$ organ and $(B)$ postmortem time, and unweighted UniFrac distances across $(C)$ organ and $(D)$ postmortem time. Analysis was performed in QIIME 2, and significance levels are as follows: $* * \mathrm{p} \leq 0.01$.

bone marrow was 7489.47 $(\min =2347, \quad \max =17,850$, $\mathrm{SD}=5048.7)$ and stomach was $14198.2 \quad(\min =1448$, $\max =96,625, \mathrm{SD}=26168.53)$. The DESeq2 mean transcript library size after filtering for the intestines was $7019(\mathrm{~min}=1045$, $\max =26,751, \mathrm{SD}=8792.68)$, heart was $31,480(\min =5492$, $\max =104,198, \quad \mathrm{SD}=33544.22), \quad$ bone marrow was 6722 $(\min =2193, \max =14,501, \mathrm{SD}=4267.12)$, and stomach was $12,828(\min =1319, \quad \max =87,270, \quad S D=23682.44)$. Significantly differentially expressed transcripts for each method were determined, but only transcripts that were reported as significant by both edgeR and DESeq2 were considered significant in the study (Table 2).

Neither the intestines, bone marrow, nor stomach contained significantly up-regulated or down-regulated transcripts from both programs. In total, the heart contained 2051 significantly up-regulated transcripts and six significantly down-regulated transcripts. The significant differences came from comparison expression levels between early and late decomposition and comparing middle and late decomposition. The early versus late comparison contained 1028 up-regulated transcripts with 252 of them being annotated as hypothetical, ribosomal, or unknown and 4 down-regulated transcripts all annotated as hypothetical. The middle versus late comparison contained 1023 up-regulated transcripts with 247 of them being annotated as hypothetical, ribosomal, or unknown and two down-regulated transcripts both having a hypothetical annotation. Out of the up-regulated transcripts, 1022 (99.8\%) were shared between the two group comparisons. The most up-regulated pathways were amino acid and carbohydrate metabolism (Fig. 6). Other notable pathways include stress response, membrane transport, sporulation, and cell motility. A complete list of the individual significant transcripts with their $\log$ FC, FDR, NCBI nr-protein annotation, and pathway annotation can be found in Online Supplemental (Table S2). 


\section{Discussion}

The differences detected between bacterial communities are attributed to the organ and/or postmortem time of the sample. The lack of diversity differences between sterilization treatments suggests that internal antemortem microbial communities give rise to the dominating internal postmortem communities during decomposition. In a previous model, we detected a similar trend

\section{A Weighted UniFrac PCoA}

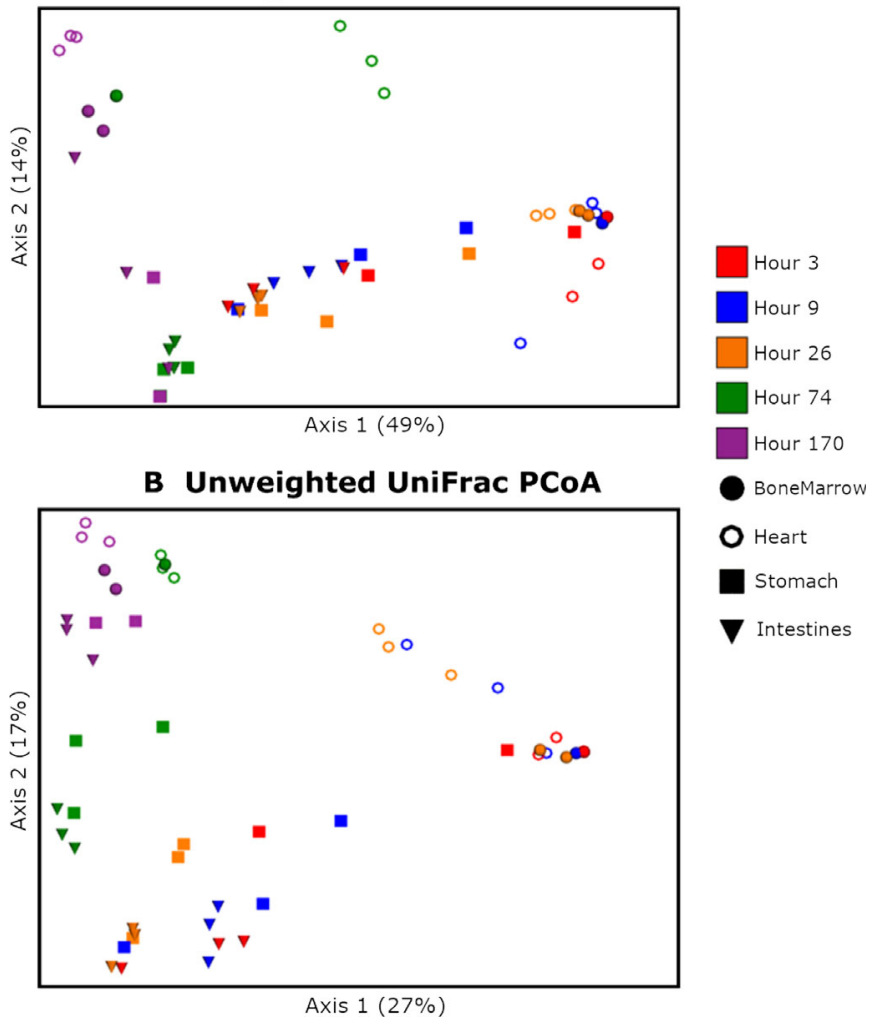

FIG. 5-PCoA plots of the mouse organ microbiome over the PMI. PCoA plots were created for both (A) weighted and (B) unweighted UniFrac distances. Colors represent the PMIs, and shapes represent the organ from where the sample was obtained. Image was created using QIIME 2 and Emperor. [Color figure can be viewed at wileyonlinelibrary.com] where the internal microbial profile was consistent across surface sterilization techniques further strengthening the hypothesis that internal microbes are the main contributors to internal host tissue breakdown and may serve as reliable PMI biomarkers (26). Additionally, we believe the introduction of $S$. aureus KUB7 and $C$. perfringens + pZMB2 did not greatly alter the existing community structure due to the low detection by highly sensitive DNA techniques. In fact, $S$. aureus KUB7 had the higher mean abundance between the two introduced species during late decomposition and was only detected above rare taxa in one 7day bone marrow sequenced sample which is a timepoint where no S. aureus KUB7 was detected using qPCR. This lack of detection in total RNA sequencing, which is less sensitive to individual species, suggests that the majority, if not all, of $S$. aureus and $C$. perfringens detected from sequencing belong to the natural host microbiota. It is important to note that we are limited in accurately assessing the extent of competition that may have occurred between the introduced species and the natural microbiota, though our data suggest a minimal impact allowing for full analysis of both the community structure and function.

When comparing the family relative abundances, we found that the intestines and stomach showed similar communities and turnover as decomposition progressed. In the first $26 \mathrm{~h} \mathrm{PMI}$, the intestines and stomachs were dominated by Lachnospiraceae which is a common intestinal tract commensal, a strict anaerobe, and has a Gram-positive cell wall helping protect the cells from the low $\mathrm{pH}$ in the stomach. Ruminococcaceae are another Grampositive taxon found in lower abundance and are strict anaerobes from in the human intestinal tract that break down complex carbohydrates (54). After $26 \mathrm{~h}$, both of these families decreased in relative abundance and Lactobacillaceae increased. Lactobacillaceae are lactic acid-producing bacteria that are generally anaerobic but many are aerotolerant. The ability to withstand oxygen is an advantageous attribute during the decomposition process as the initially anaerobic intestines increases in oxygen levels after the bloat stage as the body purges internal fluids $(2,7,16)$. Along with aerotolerance, the creation of lactic acid from fermentation has an inhibitory effect on many microbial species that cannot tolerate the low $\mathrm{pH}$ which may allow Lactobacillaceae to outcompete other families in the stomach and intestines during early decomposition. After $170 \mathrm{~h}$, Clostridiaceae I increased in relative abundance in the stomach and intestines. Clostridiaceae are common vertebrate decomposers found in late PMIs and ferment

TABLE 2-Number of transcripts detected from differential expression analysis

\begin{tabular}{|c|c|c|c|c|c|c|c|}
\hline \multirow[b]{2}{*}{ Organ } & \multirow[b]{2}{*}{ Time Comparison } & \multicolumn{2}{|c|}{$\begin{array}{c}\text { \# of Significant Up-regulated } \\
\text { Transcripts }\end{array}$} & \multicolumn{2}{|c|}{$\begin{array}{l}\text { \# of Nonsignificantly } \\
\text { Expressed Transcripts }\end{array}$} & \multicolumn{2}{|c|}{$\begin{array}{l}\text { \# of Significant Down- } \\
\text { Regulated Transcripts }\end{array}$} \\
\hline & & DESeq2 & EdgeR & DESeq2 & EdgeR & DESeq2 & EdgeR \\
\hline \multirow[t]{3}{*}{ Intestines } & Early versus middle & $0(0)$ & $42(0)$ & 15,647 & 9642 & $0(0)$ & $0(0)$ \\
\hline & Middle versus late & $0(0)$ & $2134(0)$ & 15,647 & 7470 & $0(0)$ & $62(0)$ \\
\hline & Early versus late & $0(0)$ & $3684(0)$ & 15,647 & 5977 & $0(0)$ & $5(0)$ \\
\hline \multirow[t]{3}{*}{ Heart } & Early versus middle & $276(0)$ & $0(0)$ & 19,917 & 12,945 & $6(0)$ & $0(0)$ \\
\hline & Middle versus late & $1056(1023)$ & $7073(1023)$ & 19,138 & 5859 & $5(2)$ & $13(2)$ \\
\hline & Early versus late & $1056(1028)$ & 8256 (1028) & 19,137 & 4622 & $6(4)$ & $67(4)$ \\
\hline \multirow[t]{3}{*}{ Bone marrow } & Early versus middle & $0(0)$ & $18(0)$ & 9949 & 3967 & $0(0)$ & $3(0)$ \\
\hline & Middle versus late & $0(0)$ & $45(0)$ & 9949 & 3861 & $0(0)$ & $82(0)$ \\
\hline & Early versus late & $0(0)$ & $32(0)$ & 9949 & 3911 & $0(0)$ & $45(0)$ \\
\hline \multirow[t]{3}{*}{ Stomach } & Early versus middle & $0(0)$ & $432(0)$ & 14,300 & 8771 & $0(0)$ & $28(0)$ \\
\hline & Middle versus late & $0(0)$ & $1(0)$ & 14,300 & 8800 & $0(0)$ & $430(0)$ \\
\hline & Early versus late & $0(0)$ & $0(0)$ & 14,300 & 9212 & $0(0)$ & $19(0)$ \\
\hline
\end{tabular}

Time comparisons are separated by their postmortem time groups: early $(3,9 \mathrm{~h})$, middle $(26,74 \mathrm{~h})$, and late (170 h). The number of significant transcripts from each analysis method is shown with the number of common transcripts between the two methods being in parenthesis. 

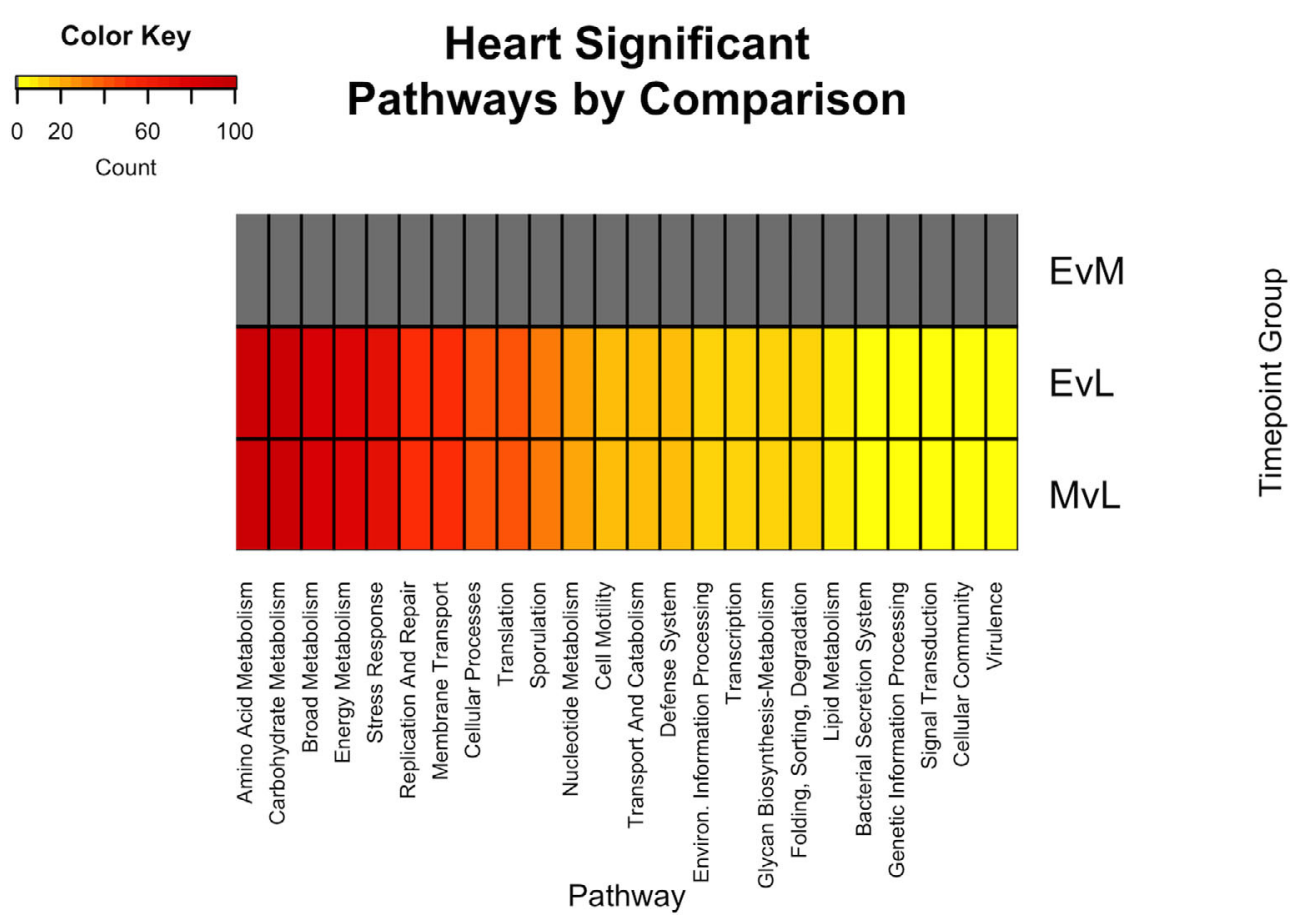

FIG. 6-Heatmap of the significant pathway regulation during timepoint group comparisons in heart. Heatmap representing the transcript count of each pathway annotated from the significant transcripts of each comparison by color. Pathway is included on the $\mathrm{x}$-axis and timepoint group (EvL $=$ early vs. late, $M v L=$ middle vs. late) on the $\mathrm{y}$-axis. Pathways that were not detected in a comparison are in gray. [Color figure can be viewed at wileyonlinelibrary.com]

amino acids and fatty acids that are found in remains $(6,7,55)$. Clostridiaceae are Gram-positive, anaerobic, and spore-forming cells, but many have the ability to withstand small amounts of oxygen (56). Clostridiaceae can grow in the anaerobic niches in the intestines until oxygen levels increase above their threshold or nutrients deplete, then start forming endospores that allow the cells to go dormant, and resist unfavorable environmental conditions. The stomach and intestine bacterial communities appeared to be stable for at least $26 \mathrm{~h}$ after death, with a dramatic shift taking place within $74 \mathrm{~h}$.

Interestingly, the heart and the femur bone marrow showed similar communities and turnover events as well, despite being in different anatomical locations. This may be due to each site being sterile or of extremely low colonization during life leading to the translocation of microorganisms to the area in search of nutrients. One of the early colonizers we detected in both the heart and the bone marrow was Nitrososphaeraceae, an archaeal family of nitrogen oxidizers. As far as we know, Nitrososphaeraceae has not been shown to be associated with the internal microbial communities of decomposition, but this may be due to the lack of forensic archaea community analyses of decomposing vertebrate remains. Nitrogen oxidation, nitrification, occurs when nitrogen levels are high, oxidizing ammonia to nitrite, releasing hydrogen protons, and creating a decrease in $\mathrm{pH}$. This process has been shown to play a role in nitrogen cycling in grave soils potentially by nitrifying Proteobacteria and is suspected to play a role in nitrogen cycling in the carcass as well $(6,57,58)$. Similarly, the intestinal fluids prerupture have been shown to contain high amounts of ammonia $(6,59)$. This suggests that the high ammonia levels detected in the intestinal environment during early decomposition are similar to those of the heart and bone marrow, which may be ultimately oxidized by Nitrososphaeraceae during early decomposition. Further investigation of abiotic factors such as oxygen, nitrogen, and $\mathrm{pH}$ will be an important next step to determine these abiotic concentrations in sterile organs. It is also important to note that some Nitrososphaeraceae species have been shown to contain flagella and are motile, which would allow for early advantageous translocation into sterile organs.

Similar to the intestines and stomach, the bone marrow had a microbial shift after $26 \mathrm{~h}$ to be dominated by Clostridiaceae while the heart began to shift after $9 \mathrm{~h}$ with both Clostridiaceae and Enterobacteriaceae increasing in relative abundance. Enterobacteriaceae are Gram-negative, anaerobes with aerotolerance, and are common inhabitants of the intestinal tract which suggests these communities have translocated from the intestines to the heart and bone marrow as decomposition progressed. The microbial shift after $26 \mathrm{~h}$ detected in internal organs is consistent with human external postmortem microbiota data by Pechal et al. (8) which demonstrated that the external human microbiota is relatively stable within $48 \mathrm{~h}$ after death, suggesting that a major microbial turnover event takes place between 48 and $74 \mathrm{~h}$. Our data suggest this pattern is consistent with the rate of bacterial community turnover in some internal organs with the only exception being the heart communities, which began to shift after $9 \mathrm{~h}$. The discrepancies between community turnover rates of internal and external organs compared to the heart merit further investigation. This post $48 \mathrm{~h}$ change likely corresponds to the transition from fresh remains to the high microbial activity anaerobic bloat stage and the subsequent rupture which introduces oxygen to the internal organs selecting for more aerotolerant species $(2,16)$.

Shannon diversity comparisons only showed a significant difference between organs and not with postmortem time or treatment. The variation likely occurs from the consistent high bacterial richness and diversity found in the intestines compared to presumed sterile antemortem organs bone marrow and heart. The stomach is colonized during life, but the bacterial abundance 
is far less than the intestines and our data suggest there is a larger variation in the bacterial abundance in the stomach across individuals than in the intestines. Comparisons of beta diversity through weighted and unweighted UniFrac distances showed that the comparisons using unweighted UniFrac tended to provide more significant comparisons than weighted. This is likely due to the nature of the calculation of the distances in which weighted takes in to account the species presence along with abundance while unweighted only takes in to account the presence or absence of a species $(60,61)$. Comparing the two weighted and unweighted distance, comparisons by organs differ when it comes to the stomach due to high variation, but the overarching results suggest that there is a stark difference between the intestines and the heart and bone marrow in beta diversity, with the stomach being more similar to the intestines. Beta diversity analyses of the postmortem times confirm what we suspected from the relative abundances, in that the first $26 \mathrm{~h}$ is relatively stable and a turnover event takes place by $74 \mathrm{~h}$ postmortem. This separation between the known colonized organs and others was seen in the PCoA plots along with the stabilization of the under 26-h communities since the early samples were seen clustering near each other. Data based solely on the microorganisms detected showed microbial convergence in all organs. However, data weighted by abundance yielded clustering and separation of the intestines/stomach and heart/bone marrow cluster at late stages of decomposition. This is likely due to the fact the while all organs contained Clostridiaceae and Lactobacillaceae, the ratio between the two differed based on the organ. The importance of these two families was ultimately confirmed with ANCOM showing their significantly different abundances across postmortem times in each organ. Differences across organs may be due to antemortem colonization of the intestines and stomach compared to colonizing sites postmortem, competition between species, or a difference in the nutrients available leading to selection of organisms that can better utilize what is present. Similarly, the turnover event after $26 \mathrm{~h}$ is likely due to the same variables. In an effort to better understand how the bacterial taxa were reacting to this shift, we turned our focus to the functional pathways being regulated.

The functional capabilities of organisms' present can help elucidate factors driving the microbial turnover by investigating which pathways are being regulated. Commensal and transient microflora co-evolve and co-exist on and within their host and cover skin and human mucosal surfaces (62). The living host supplies resident microbes with adequate surface area, nutrients, oxygen, temperature, and $\mathrm{pH}$, and these microflorae grow to a maximum growth rate $(63,64)$. Fluctuations of these parameters affect growth and activate microbial stress responses $(65,66)$. Bacteria respond to stress and dynamic environmental conditions by modulating gene expression that controls the cell's structure and function $(64,65)$, and an extreme stress will force some microbes to dormancy or death (66). Competition and dispersal among microbial communities also occur when resources become limited $(63,67)$. Modulation of gene expression or shifts in microbial populations can be measured to determine associations that exist with physical and chemical conditions within micro- and macroenvironments. Biomarkers from expression of indicator genes thus have the potential to monitor particular changes at early stages or long-term stages of decomposition, where their status reflects and/or predicts the conditions of the environment where they are found. However, bacterial mRNA is short-lived, ranging only from minutes to hours (68). Therefore, it is necessary for preservation methods to be undertaken, such as with RNAlater or some other nucleic acid stabilizer, or immediate freezing in order to control degradation. However, an understanding of how microbial genes, and ultimately the proteins they encode, function during host decomposition, will provide a foundation for the development of biochemical assays with potential for quantifying evidentiary metrics such as PMI estimates in a forensic investigation.

In this study, we are the first to our knowledge to extract total RNA to be able to identify the microbial communities present along with the functional pathways they are actively utilized at different stages of decomposition. A concern with only focusing on the bacterial community structure is that human microbial profiles are dependent on the individual, and species variance across individuals can interfere with the presence of certain taxa. This can cause issues if forensic biomarker taxa are not associated with that individual at the time of death. Being able to obtain functional data of active taxa that are present along with structural data may circumvent this concern because, while specific taxa may change between people, functions needed for microbes to survive across PMIs should be redundant. Therefore, coupling community structural and functional profiles may provide evidence less biased to the individual's antemortem microbiome that may be used for biomarker detection.

Understanding that a community structural turnover event takes place sometime between 26 and $74 \mathrm{~h}$, we stratified functional analysis into three parts: early, middle, and late. We expected the comparison of differentially expressed transcripts between the early and middle time groups to be similar if the communities are still functionally redundant, and that is exactly what data showed. Significant differentially expressed transcripts between metabolic pathways did not occur until early and middle timepoints were compared with the late 170-h timepoint, and the heart was the only organ to contain significant differential expression. We hypothesize the heart goes through a significant functional shift due to its drastic shift in bacterial community structure as Clostridiaceae and Enterobacteriaceae dominate during late decomposition. Interestingly, the significant metabolic pathways and individual transcripts that were up-regulated during late decomposition were almost identical in both the early and middle decomposition time groups further underscoring that a major change occurred in the body after $26 \mathrm{~h}$ postmortem affecting not only the bacterial community structure, but also their function.

The increase in amino acid and carbohydrate metabolism suggests that nutritional utilization is a key factor in determining which species dominate. Energy metabolism increases predominately related to oxidative phosphorylation which correlates with the increase in aerobic respiration after the body ruptures (16,59). A few interesting pathways we saw were stress response, sporulation, and cell motility. These allow organisms an advantage by allowing adaptation to adverse environmental conditions, such as with adaptation to temperature (stress response), sporulation, or the ability to translocate within the body in search for nutrients (motility). These were not identified in bone marrow, likely due to the relatively small transcripts obtained. The intestines and stomach community functions may not change drastically enough between time groups, although the community structure does still change. It is possible the community turnover in the intestines and stomach is caused by the ability to replicate or acquire nutrients more efficiently within the same pathway as a competitor instead of the ability to use different pathways, but this still needs to be elucidated. 
With this and our previously conducted study, we have established a murine model of microbial transmigration, community assemblage succession, and functional modulation across early decomposition time. The use of a vertebrate surrogate model has historically provided researchers the ability to obtain statistically meaningful data that have forwarded basic and applied sciences in hypothesis testing and human data validation. Forensic science is also one that ultimately improves the welfare of humanity and of animals, and the use of vertebrate surrogates has been a common practice in studying the microbial ecology of decomposition for refining PMI estimates and other forensic relevant questions [for instance, please see: (4,6,7,16,69-71)]. The purpose of our study was to determine a baseline for microbial transmigration, assemblage, and gene expression in association with time since death in order to better refine PMI estimates, and our established model allowed us the ability to control PMI and sample size, variables that are often limited with the use of donated cadavers.

In this study, we have demonstrated the use of total RNA as a more cost-efficient method to obtain both community structural and functional data to aid in microbial PMI estimations. We have shown the taxonomic information extracted computationally from total RNA sequencing is comparable with sequencing of $16 \mathrm{~S}$ rRNA without amplifying the $16 \mathrm{~S}$ rRNA gene which can lead to overinflated diversity estimates from sequencing errors $(72,73)$. However, the cost of whole genome sequencing is larger, sequencing costs continue to decrease, and with this methodology, researchers can obtain structural and functional data from a single nucleic acid isolation allowing for more accurate comparisons of the community and its function. This is also one of the first studies to provide a broad analysis of functional pathway regulation of active bacterial communities during decomposition. This is a first step into being able to deeply analyze functional pathways and individual transcripts in conjunction with taxonomic analysis of active communities at varying stages of decomposition. Understanding these shifts in community composition and gene expression patterns will benefit studies in decomposition ecology and forensic science, aiding in biomarker discovery for PMI estimation.

\section{Acknowledgments}

We would like to thank Andrew Bryant for his work assisting in nucleic acid extractions and quantitative PCR data collection.

\section{References}

1. Burcham ZM, Hood JA, Pechal JL, Krausz KL, Bose JL, Schmidt CJ, et al. Fluorescently labeled bacteria provide insight on post-mortem microbial transmigration. Forensic Sci Int 2016;264:63-9.

2. Janaway R, Percival S, Wilson A. Decomposition of human remains. In: Percival S, editor. Microbiology and aging: clinical manifestations. New York, NY: Springer Science and Business Media, 2009;313-34.

3. Knight B. Forensic medicine, 11th edn. Oxford, UK: Oxford University Press, 1997.

4. Carter D, Metcalf J, Bibat A, Knight R. Seasonal variation of postmortem microbial communities. Forensic Sci Med Pathol 2015;11(2):202-7.

5. Carter D, Yellowlees D, Tibbett M. Moisture can be the dominant environmental parameter governing cadaver decomposition in soil. Forensic Sci Int 2010;200(1-3):60-6.

6. Metcalf JL, Xu ZZ, Weiss S, Lax S, Van Treuren W, Hyde ER, et al. Microbial community assembly and metabolic function during mammalian corpse decomposition. Science 2016;351(6269):158-62.

7. Pechal J, Crippen T, Benbow M, Tarone A, Dowd S, Tomberlin J. The potential use of bacterial community succession in forensics as described by high throughput metagenomic sequencing. Int J Legal Med 2014;128 (1):193-205.
8. Pechal JL, Schmidt CJ, Jordan HR, Benbow ME. A large-scale survey of the postmortem human microbiome, and its potential to provide insight into the living health condition. Sci Rep 2018;8(1):5724-5739.

9. Lax S, Hampton-Marcell J, Gibbons S, Colares G, Smith D, Eisen J, et al. Forensic analysis of the microbiome of phones and shoes. Microbiome 2015;3:21-29.

10. Lax S, Smith D, Hampton-Marcell J, Owens S, Handley K, Scott N, et al. Longitudinal analysis of microbial interaction between humans and the indoor environment. Science 2014;345(6200):1048-52.

11. Leake SL, Pagni M, Falquet L, Taroni F, Greub G. The salivary microbiome for differentiating individuals: proof of principle. Microbes Infect 2016;18(6):399-405.

12. Luongo JC, Barberan A, Hacker-Cary R, Morgan EE, Miller SL, Fierer N. Microbial analyses of airborne dust collected from dormitory rooms predict the sex of occupants. Indoor Air 2017;27(2):338-44.

13. Meadow J, Altrichter A, Green J. Mobile phones carry the personal microbiome of their owners. PeerJ 2014;2:e447.

14. Tridico S, Murray D, Addison J, Kirkbride K, Bunce M. Metagenomic analyses of bacteria on human hairs: a qualitative assessment for applications in forensic science. Investig Genet 2014;5(1):16-30.

15. Harmsen D, Karch H. 16s rDNA for diagnosing pathogens: a living tree. ASM News 2004;70:19-24.

16. Metcalf JL, Wegener Parfrey L, Gonzalez A, Lauber CL, Knights D, Ackermann G, et al. A microbial clock provides an accurate estimate of the postmortem interval in a mouse model system. eLife 2013;2:e01104.

17. Cobaugh K, Schaeffer S, DeBruyn J. Functional and structural succession of soil microbial communities below decomposing human cadavers. PLoS ONE 2015;10(6):e0130201.

18. Dickson G, Poulter R, Maas E, Probert P, Kieser J. Marine bacterial succession as a potential indicator of postmortem submersion interval. Forensic Sci Int 2011;209(1-3):1-10.

19. Hauther KA, Cobaugh KL, Jantz LM, Sparer TE, DeBruyn JM. Estimating time since death from postmortem human gut microbial communities. J Forensic Sci 2015;60(5):1234-40.

20. Tolbert M, Finley SJ, Visona SD, Soni S, Osculati A, Javan GT. The thanatotranscriptome: gene expression of male reproductive organs after death. Gene 2018;675:191-6.

21. Javan GT, Finley SJ, Can I, Wilkinson JE, Hanson JD, Tarone AM. Human thanatomicrobiome succession and time since death. Sci Rep 2016;6:29598.

22. Kellerman GD, Waterman NG, Scharefenberger LF. Demonstration in vitro of postmortem bacterial transmigration. Am J Clin Pathol 1976;66(5):911-5.

23. Tuomisto S, Karhunen PJ, Vuento R, Aittoniemi J, Pessi T. Evaluation of postmortem bacterial migration using culturing and real-time quantitative PCR. J Forensic Sci 2013;58(4):910-6.

24. Melvin JR Jr, Cronholm LS, Simson LR Jr, Isaacs AM. Bacterial transmigration as an indicator of time of death. J Forensic Sci 1984;29 (2):412-7.

25. Hyde ER, Metcalf JL, Bucheli SR, Lynne AM, Knight R. Microbial communities associated with decomposing corpses. In: Carter DO, Tomberlin JK, Benbow ME, Metcalf JL, editors. Forensic microbiology. Hoboken, NJ: Wiley, 2017;245-73.

26. Burcham ZM, Pechal JL, Schmidt CJ, Bose JL, Rosch JW, Benbow $\mathrm{ME}$, et al. Bacterial community succession, transmigration, and differential gene transcription in a controlled vertebrate decomposition model. Front Microbiol 2019;10. https://doi.org/10.3389/fmich.2019.00745.

27. Pozhitkov AE, Neme R, Domazet-Loso T, Leroux BG, Soni S, Tautz D, et al. Tracing the dynamics of gene transcripts after organismal death. Open Biol 2017;7(1):160267.

28. Louca S, Polz MF, Mazel F, Albright MBN, Huber JA, O'Connor MI, et al. Function and functional redundancy in microbial systems. Nat Ecol Evol 2018;2(6):936-43.

29. Langenheder S, Lindstrom ES, Tranvik LJ. Structure and function of bacterial communities emerging from different sources under identical conditions. Appl Environ Microbiol 2006;72(1):212-20.

30. Williamson H, Phillips R, Sarfo S, Wansbrough-Jones M, Small P. Genetic diversity of PCR-positive, culture-negative and culture-positive Mycobacterium ulcerans isolated from Buruli ulcer patients in Ghana. PLoS ONE 2014;9(2):e88007.

31. Takamizawa A, Miyata S, Matsushita O, Kaji M, Taniguchi Y, Tamai E, et al. High-level expression of clostridial sialidase using a ferredoxin gene promoter-based plasmid. Protein Expr Purif 2004;36(1):70-5.

32. Krueger F. TrimGalore: a wrapper around Cutadapt and FastQC to consistently apply quality and adapter trimming to FastQ files. 2015. http:// www.bioinformatics.babraham.ac.uk/projects/trim_galore/ (accessed April 25, 2019). 
33. Bolger AM, Lohse M, Usadel B. Trimmomatic: a flexible trimmer for Illumina sequence data. Bioinformatics 2014;30(15):2114-20.

34. Westreich ST, Treiber ML, Mills DA, Korf I, Lemay DG. SAMSA2: a standalone metatranscriptome analysis pipeline. BMC Bioinform 2018;19(1):175

35. Zhang J, Kobert K, Flouri T, Stamatakis A. PEAR: a fast and accurate illumina paired-end reAd mergeR. Bioinformatics 2014;30(5):614-20.

36. Kopylova E, Noe L, Touzet H. SortMeRNA: fast and accurate filtering of ribosomal RNAs in metatranscriptomic data. Bioinformatics 2012;28 (24):3211-7.

37. Quast C, Pruesse E, Yilmaz P, Gerken J, Schweer T, Yarza P, et al. The SILVA ribosomal RNA gene database project: improved data processing and web-based tools. Nucleic Acids Res 2013;41(Database issue):D590-6.

38. Caporaso JG, Kuczynski J, Stombaugh J, Bittinger K, Bushman FD, Costello EK, et al. QIIME allows analysis of high-throughput community sequencing data. Nat Methods 2010;7(5):335-6.

39. Callahan BJ, McMurdie PJ, Rosen MJ, Han AW, Johnson AJ, Holmes SP. DADA2: high-resolution sample inference from Illumina amplicon data. Nat Methods 2016;13(7):581-3.

40. Kazutaka K, Standley DM. MAFFT multiple sequence alignment software version 7: improvements in performance and usability. Mol Biol Evol 2013;30(4):772-80.

41. Lane DJ. 16s/23s rrna sequencing. In: Stackebrandt E, Goodfellow M, editors. Nucleic acid techniques in bacterial systematics. New York, NY: John Wiley and Sons, 1991;115-75.

42. Price MN, Dehal PS, Arkin AP. FastTree 2-approximately maximumlikelihood trees for large alignments. PLoS ONE 2010;5(3):e9490.

43. Yilmaz P, Parfrey LW, Yarza P, Gerken J, Pruesse E, Quast C, et al The SILVA and "All-species Living Tree Project (LTP)" taxonomic frameworks. Nucleic Acids Res 2014;42(Database issue):D643-8.

44. Rognes T, Flouri T, Nichols B, Quince C, Mahe F. VSEARCH: a versatile open source tool for metagenomics. PeerJ 2016;4:e2584.

45. Bokulich NA, Kaehler BD, Rideout JR, Dillon M, Bolyen E, Knight R, et al. Optimizing taxonomic classification of marker-gene amplicon sequences with QIIME 2's q2-feature-classifier plugin. Microbiome 2018;6(1):90-107.

46. Lozupone CA, Hamady M, Kelley ST, Knight R. Quantitative and qualitative beta diversity measures lead to different insights into factors that structure microbial communities. Appl Environ Microbiol 2007;73(5):1576-85.

47. Mandal S, Van Treuren W, White RA, Eggesbo M, Knight R, Peddada SD. Analysis of composition of microbiomes: a novel method for studying microbial composition. Microb Ecol Health Dis 2015;26:27663.

48. Buchfink B, Xie C, Huson DH. Fast and sensitive protein alignment using DIAMOND. Nat Methods 2015;12(1):59-60.

49. Robinson MD, McCarthy DJ, Smyth GK. edgeR: a Bioconductor package for differential expression analysis of digital gene expression data. Bioinformatics 2010;26(1):139-40.

50. McCarthy DJ, Chen Y, Smyth GK. Differential expression analysis of multifactor RNA-Seq experiments with respect to biological variation. Nucleic Acids Res 2012;40(10):4288-97.

51. Love MI, Huber W, Anders S. Moderated estimation of fold change and dispersion for RNA-seq data with DESeq2. Genome Biol 2014;15 (12):550.

52. Kanehisa M, Goto S. KEGG: kyoto encyclopedia of genes and genomes. Nucleic Acids Res 2000;28(1):27-30.

53. The UniProt $\mathrm{C}$. UniProt: the universal protein knowledgebase. Nucleic Acids Res 2017;45(D1):D158-69.

54. Biddle A, Steward L, Blanchard J, Leschine S. Untangling the genetic basis of fibrolytic specialization by Lachnospiraceae and Ruminococcaceae in diverse gut communitites. Diversity 2013;5(3):627-40.

55. Can I, Javan GT, Pozhitkov AE, Noble PA. Distinctive thanatomicrobiome signatures found in the blood and internal organs of humans. J Microbiol Methods 2014;106:1-7.

56. Hillmann F, Fischer RJ, Saint-Prix F, Girbal L, Bahl H. PerR acts as a switch for oxygen tolerance in the strict anaerobe Clostridium acetobutylicum. Mol Microbiol 2008;68(4):848-60.

57. Carter DO, Tibbett M. Does repeated burial of skeletal muscle tissue (Ovis aries) in soil affect subsequent decomposition? Appl Soil Ecol 2008;40(3):529-35.

58. Anderson B, Meyer J, Carter DO. Dynamics of ninhydrin-reactive nitrogen and $\mathrm{pH}$ in gravesoil during the extended postmortem interval. J Forensic Sci 2013;58(5):1348-52.

59. Janaway RC, Percival SL, Wilson AS. Decomposition of human remains. In: Percival SL, editor. Microbiology and aging. New York, NY: Springer Science + Business Media, LLC, 2009;313-34
60. Lozupone C, Knight R. UniFrac: a new phylogenetic method for comparing microbial communities. Appl Environ Microbiol 2005;71 (12):8228-35.

61. Lozupone C, Lladser ME, Knights D, Stombaugh J, Knight R. UniFrac: an effective distance metric for microbial community comparison. ISME J 2011;5(2):169-72.

62. The Human Microbiome Consortium. A framework for human microbiome research. Nature 2012;486(7402):215-21.

63. Boor KJ. Bacterial stress responses: what doesn't kill them can make then stronger. PLoS Biol 2006;4(1):e23.

64. Cotter PD, Hill C. Surviving the acid test: responses of gram-positive bacteria to low $\mathrm{pH}$. Microbiology and molecular biology reviews. Microbiol Mol Biol Rev 2003;67(3):429-53.

65. Ron EZ. Editorial: an update on the bacterial stress response. Res Microbiol 2009;160(4):243-4.

66. Schimel J, Balser TC, Wallenstein M. Microbial stress-response physiology and its implications for ecosystem function. Ecology 2007;88 (6):1386-94.

67. Cornforth DM, Foster KR. Competition sensing: the social side of bacterial stress responses. Nat Rev Microbiol 2013;11(4):285-93.

68. Laalami S, Zig L, Putzer H. Initiation of mRNA decay in bacteria. Cell Mol Life Sci 2014;71(10):1799-828.

69. Lauber CL, Metcalf JL, Keepers K, Ackermann G, Carter DO, Knight R. Vertebrate decomposition is accelerated by soil microbes. Appl Environ Microbiol 2014;80(16):4920-9.

70. Benninger LA, Carter DO, Forbes SL. The biochemical alteration of soil beneath a decomposing carcass. Forensic Sci Int 2008;180(23):70-5.

71. Carter DO, Yellowlees D, Tibbett M. Temperature affects microbial decomposition of cadavers (Rattus rattus) in contrasting soils. Appl Soil Ecol 2008;40(1):129-37.

72. Kunin V, Engelbrektson A, Ochman H, Hugenholtz P. Wrinkles in the rare biosphere: pyrosequencing errors can lead to artificial inflation of diversity estimates. Environ Microbiol 2010;12(1):118-23.

73. Oulas A, Pavloudi C, Polymenakou P, Pavlopoulos GA, Papanikolaou N, Kotoulas G, et al. Metagenomics: tools and insights for analyzing next-generation sequencing data derived from biodiversity studies. Bioinform Biol Insights 2015;9:75-88.

\section{Supporting Information}

Additional Supporting Information may be found in the online version of this article:

Figure S1. S. aureus KUB7 Detection across Organs over Decomposition. Linear plot representing the $\log$ genomic units of S. aureus KUB7 detected in the A. kidneys, B. skin, C. spleen, D. lungs, and E. liver as determined by RFP gene detection.

Figure S2. S. aureus KUB7 Detection across Organs over Decomposition. Linear plot representing the $\log$ genomic units of $S$. aureus KUB7 detected in the A. intestines, B. stomach, C. heart, and $\mathbf{D}$. bone marrow as determined by RFP gene detection.

Figure S3. C. perfringens + pZMB2 Detection across Organs over Decomposition. Linear plot representing the log genomic units of C. perfringens + pZMB2 detected in the A. kidneys, $\mathbf{B}$. skin, C. spleen, D. lungs, and E. liver as determined by CFP gene detection.

Figure S4. C. perfringens + pZMB2 detection across organs over decomposition. Linear plot representing the log genomic units of $C$. perfringens + pZMB2 detected in the A. intestines, B. stomach, C. heart, and $\mathbf{D}$. bone marrow as determined by CFP gene detection.

Table S1. Pairwise-PERMANOVA analysis on Unifrac organ and postmortem time comparisons.

Table S2. Heart EARLY versus late PMI. 